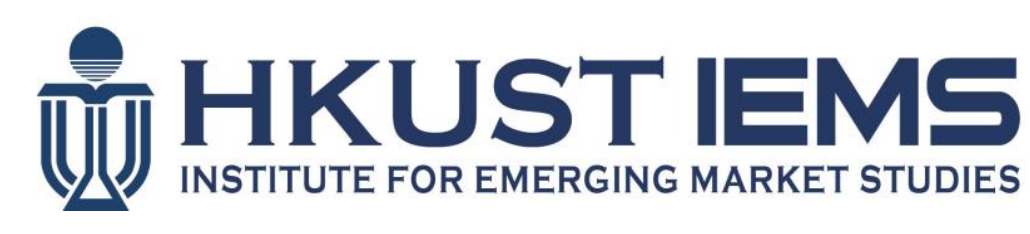

\title{
Financing Smallholder Agriculture: An Experiment with Agent-Intermediated Microloans in India
}

\author{
Pushkar MAITRA, Sandip MITRA, Dilip MOOKHERJEE, Alberto \\ MOTTA, Sujata VISARIA
}

HKUST IEMS Working Paper No. 2015-23

April 2015

HKUST IEMS working papers are distributed for discussion and comment
purposes. The views expressed in these papers are those of the authors
and do not necessarily represent the views of HKUST IEMS.
$\begin{aligned} & \text { More HKUST IEMS working papers are available at: } \\ & \text { http://iems.ust.hk/WP }\end{aligned}$




\title{
Financing Smallholder Agriculture: An Experiment with Agent-Intermediated Microloans in India
}

\author{
Pushkar MAITRA, Sandip MITRA, Dilip MOOKHERJEE, Alberto MOTTA, Sujata VISARIA
}

HKUST IEMS Working Paper No. 2015-23

April 2015

\begin{abstract}
Recent evaluations of traditional microloans have not found significant impacts on borrower production or incomes. We examine whether this can be remedied by delegating selection of borrowers for individual liability loans to local trader-lender agents incentivized by repayment-based commissions. In a field experiment in West Bengal this design (called TRAIL) was offered in randomly selected villages. In remaining villages five-member groups self-formed and applied for joint liability loans (called $G B L$ ) with otherwise similar terms. TRAIL loans increased production of potato (a leading cash crop) and farm incomes by 27-37\%, whereas GBL loans had insignificant and highly dispersed effects. Both schemes achieved equally high repayment rates, while TRAIL loans had higher take-up rates and lower administrative costs. We argue the results can be partly explained by differences in selection patterns with respect to borrower risk and productivity characteristics.
\end{abstract}

\section{Author's contact information}

Pushkar Maitra

Department of Economics

Monash University

Clayton Campus, VIC 3800

Australia

E: Pushkar.Maitra@monash.edu

\section{Sandip Mitra}

Sampling and Ocial Statistics Unit Indian Statistical Institute 203 B.T. Road, Kolkata 700108 India

E: Sandip@isical.ac.in 
Dilip Mookherjee

Department of Economics

Boston University

270 Bay State Road, Boston, MA 02215

USA

E: dilipm@bu.edu

Alberto Motta

School of Economics

University of New South Wales

NSW 2052, Australia

E: motta@unsw.edu.au

Sujata Visaria

Department of Economics

Hong Kong University of Science and Technology

Clear Water Bay, Kowloon

Hong Kong

E: svisaria@ust.hk 


\title{
Financing Smallholder Agriculture: An Experiment with Agent-Intermediated Microloans in India *
}

\author{
Pushkar Maitra ${ }^{\dagger}$ Sandip Mitra $\ddagger$ Dilip Mookherjee \\ Alberto Motta and Sujata Visariall
}

March 2015

\begin{abstract}
Recent evaluations of traditional microloans have not found significant impacts on borrower production or incomes. We examine whether this can be remedied by delegating selection of borrowers for individual liability loans to local trader-lender agents incentivized by repayment-based commissions. In a field experiment in West Bengal this design (called TRAIL) was offered in randomly selected villages. In remaining villages five-member groups self-formed and applied for joint liability loans (called GBL) with otherwise similar terms. TRAIL loans increased production of potato (a leading cash crop) and farm incomes by $27-37 \%$, whereas GBL loans had insignificant and highly dispersed effects. Both schemes achieved equally high repayment rates, while TRAIL loans had higher take-up rates and lower administrative costs. We argue the results can be partly explained by differences in selection patterns with respect to borrower risk and productivity characteristics.
\end{abstract}

Key words: Agricultural Finance, Agent Based Lending, Group Lending, Selection, Repayment

JEL Codes: D82, O16

\footnotetext{
*Funding was provided by the Australian Agency for International Development, the International Growth Centre, United States Agency for International Development and the Hong Kong Research Grants Council. We are grateful to Shree Sanchari for implementing the lending schemes. Jingyan Gao, Clarence Lee, Daijing Lv, Foez Mojumder, Moumita Poddar and Nina Yeung provided exceptional research assistance and Elizabeth Kwok provided excellent administrative support. Boston University Masters students Torry Ah-Tye, Ou Bai, Juan Blanco, Chantel Pfeiffer and Stefan Winata conducted useful analysis and provided insights from a field study of relations between agents and borrowers in the study. We thank Xavier Gine, Albert Park, Russell Toth, Bruce Wydick and a large number of seminar and conference participants for helpful comments on previous and related versions. Internal review board clearance was received from Monash University, Boston University and the Hong Kong University of Science and Technology. The authors are responsible for all errors.

${ }^{\dagger}$ Pushkar Maitra, Department of Economics, Monash University, Clayton Campus, VIC 3800, Australia. Pushkar.Maitra@monash.edu.

${ }^{\ddagger}$ Sandip Mitra, Sampling and Official Statistics Unit, Indian Statistical Institute, 203 B.T. Road, Kolkata 700108, India. Sandip@isical.ac.in.

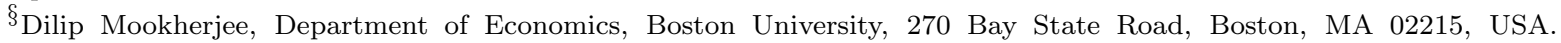
dilipm@bu.edu.

『Alberto Motta, School of Economics, University of New South Wales, NSW 2052, Australia. motta@unsw.edu.au.

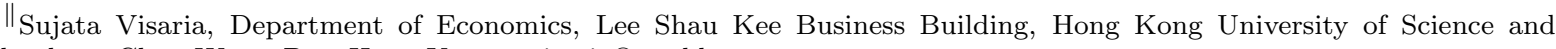
Technology, Clear Water Bay, Hong Kong. svisaria@ust.hk.
} 


\section{Introduction}

Microcredit was famously heralded as a solution to global poverty; yet experiments across a range of developing and middle income countries have found no evidence of significant impacts on borrower incomes or productivity (see Kaboski and Townsend, 2011, Banerjee, Karlan, and Zinman, 2015). This is particularly true for experiments evaluating "traditional" group-based lending schemes, in which financial institutions devolve selection, monitoring and enforcement to borrower groups. It has been difficult to identify the exact reasons for this failure. Some research has argued that the joint liability tax inherent in group lending dampens borrowers' incentives to take the risks that are essential for small entrepreneurs to succeed (Fischer, 2013). Risk-taking may also be discouraged by monitoring and pressure exerted by group members or loan officers, who bear part of the downside risk of the project but do not receive any of the upside benefits. A number of experiments with individual liability loans have been carried out where screening by loan officers and collateral have replaced some of the traditional roles played by groups, but these have also not succeeded in raising borrower incomes (Giné and Karlan, 2014, Attanasio, Augsburg, Haas, Fitzsimons, and Harmgart, 2011). Other experiments have relaxed the rigid loan durations and repayment schedules that arguably restrict borrowers' flexibility in project choice (Field, Pande, Papp, and Rigol, 2013, Feigenberg, Field, and Pande, 2013). However no intervention so far has achieved significant increases in borrower productivity and incomes, while maintaining repayment rates and administrative costs on par with traditional microcredit. ${ }^{1}$

This paper reports on an experiment with a novel variant of individual liability loans that we call TRAIL (Trader-Agent-Intermediated Individual Loans). The main innovation is to tap into the information in the local community about creditworthiness of specific borrowers. The selection of borrowers is devolved to a local intermediary with extensive experience in lending and trading within the community. In contrast to previous experiments with individual liability loans, this elicits information not otherwise available to loan officers, and eliminates the need for collateral. The local agent is incentivized through commissions linked to loan repayments, which encourages him to select productive and reliable borrowers. The agent bears limited penalties for borrower defaults, via termination clauses and modest deposits that he posts upfront, which are forfeited when repayment rates fall below a threshold. The agent's formal role in the scheme is limited to privately recommending borrowers to the microfinance institution (MFI). The MFI lends directly to recommended clients at pre-set terms, makes no effort to monitor borrowers, and remains responsible for loan recovery.

To ensure poor borrowers are targeted, the agent is only allowed to recommend individuals who own less than a specified threshold of cultivable land. There is no role for borrower

\footnotetext{
${ }^{1}$ Previous interventions that have increased borrower incomes have come at a significant cost. For example, Field, Pande, Papp, and Rigol (2013) find that increasing the grace repayment period for individual liability microloans increased weekly business profits by $41 \%$ and household incomes by almost $20 \%$, but caused a tripling of default rates.
} 
groups, group meetings or periodic savings contributions. Borrower repayment incentives are provided in standard ways by pegging the loan interest rate below the informal credit market rate, and through fast growth in the credit limit if the current loan is repaid. The underlying idea is that if the incentives of agents and borrowers are properly aligned, productive low-risk borrowers will be selected, and will thereafter not be constrained by elaborate monitoring mechanisms that inhibit entrepreneurship and risk-taking.

The principal question addressed by this paper is whether such a modified microcredit program can raise borrower productivity and incomes, without compromising the standards of repayment and administrative costs established by traditional programs. We view this as the first-order question concerning the potential role of microcredit in development, especially in light of the recent experimental evidence described above. By its very nature, TRAIL differs from traditional joint liability on multiple dimensions: mode of borrower selection (agents versus self-forming groups), incentives (individual versus joint liability loans), control (monitoring and enforcement by group members, absent in TRAIL) and social capital ("vertical" links between trader/lender and borrowers, rather than "horizontal" links between borrowers). Separating out the respective roles of these different factors and possible interactions among them is a forbidding task, infeasible logistically and financially within the context of a single experiment (Banerjee, 2013); accordingly we do not aim to do so.

Our objective is primarily to examine whether delegation of borrower selection to local intermediaries is a promising direction for microcredit, judged by impacts on borrower production and incomes. We use as a benchmark a group-based lending (GBL) approach with self-forming five member groups and joint liability loans. Apart from method of selection and liability, terms of loans were the same across the two schemes. Besides evaluating loan treatment effects on production and income in either scheme, we also examine their respective selection patterns pertaining to borrower productivity and risk characteristics (inferred from data on production and informal loans) and the extent to which these help explain the observed treatment effects.

The experiment was conducted in a set of villages in the Indian state of West Bengal over a three year span, from 2010 to 2013. The loans were designed so that they could be used to finance working capital for the cultivation of potatoes, the leading cash crop in the state. Loans were given out during the potato planting season. Repayment was due in a single lumpsum at the end of four months, when potatoes were harvested. If a borrower repaid satisfactorily, he became eligible for another four-month loan which could be used to store potatoes for later sale, or to plant other crops. The loans featured index insurance, so that the repayment amount due was adjusted downward if revenues per acre in the village fell below a 3-year moving average. Dynamic repayment incentives were provided: each subsequent loan size was $133 \%$ of the current principal repaid. The interest rate charged was $18 \%, 8$ percentage points below the average interest rate for non-collateralized loans of similar duration on the informal market.

Each intervention (TRAIL, GBL) was randomly assigned to 24 villages. They were designed 
to enable us to separately estimate selection effects and loan treatment effects conditional on selection. In TRAIL villages, an agent was randomly selected from a list of established trader-lenders, and thereafter asked to recommend 30 borrowers satisfying stipulated criteria. TRAIL loans were offered to 10 borrowers chosen randomly from those recommended by the agent. Comparisons between those recommended and not offered the loans (called Control 1 households) and those not recommended (Control 2) provide estimates of selection effects, while between those offered the loans (the Treatment group) and Control 1 households generate estimates of TRAIL treatment effects conditional on selection. In GBL, loans featured the same interest rate, loan duration, growth in credit access and covariate risk insurance as TRAIL. The only difference was that as in traditional microcredit practice, GBL loans involved joint rather than individual liability. Village residents formed 5-member groups, attended monthly meetings with loan officers and made mandated savings deposits. All groups that met these requirements over an initial screening period were included in the pool of eligible groups, out of which two randomly chosen groups were offered GBL loans. The 10 households in these two groups constitute the GBL treatment group. Comparisons of outcomes with the households in groups that had formed but were not chosen (Control 1) provide estimates of GBL loan treatment effects conditional on selection. Comparisons between the Control 1 households and households that did not form groups (Control 2) generate estimates of GBL selection effects.

The experiment ran for 3 years (2010-2013), which allows us to examine the long term impacts of the program. We conducted household surveys every four months, to record sample households' cultivation decisions, harvest and sales of all crops they grew. The high frequency data collection helped lower measurement error and the role of random exogenous factors affecting production and income outcomes. Moreover, there was no attrition in our sample.

The intent-to-treat treatment estimates of the two programs are as follows. Compared to households that were recommended by the agent but were not offered loans, those that were offered the TRAIL loans had $37 \%$ higher value added in potato production and $29 \%$ higher value added aggregated across all crops. These differences were statistically significant at the $1 \%$ level. In contrast, GBL loans increased value added in potatoes by $13 \%$, and across all crops by $0.3 \%$; both were indistinguishable from zero at conventional levels of significance. We also find evidence that borrowers recommended by the TRAIL agent were more productive than those not recommended. The point estimates of the implied rates of return on the expansion in cultivation costs financed by the loans were substantially higher in the TRAIL scheme: 115\% (127\%) annualized returns compared with 39\% (16\%) in the GBL scheme for incomes from potato cultivation (aggregate farm income). These differences are statistically significant.

Repayment rates were equally high in both the TRAIL and GBL schemes, averaging 93\% over the 3 years, but loan take-up rates were significantly higher in TRAIL. ${ }^{2}$ We also

\footnotetext{
${ }^{2} 91.6 \%$ of households that were offered TRAIL loans took the loan in Cycle 1. At the end of three years, the take-up rate was $61.7 \%$. In GBL the take-up rate is $88.2 \%$ to begin with, falling to $49 \%$ by the
} 
find no evidence that TRAIL agents siphoned off the benefits of treated borrowers by manipulating terms of other trading relationships with them. Finally the TRAIL scheme had significantly lower operational costs than the GBL scheme. As the TRAIL agent and the MFI implementing GBL were both paid commissions set at $75 \%$ of interest repayments, the bulk of TRAIL's cost savings came from lower outlays on loan officers' salaries and transport, owing to the elimination of frequent meetings of loan officers with borrowers.

Thereafter we examine differences in borrower selection patterns between TRAIL and GBL, and the extent to which this helps explain their respective impacts. We provide a theoretical explanation of these patterns and how they generate different predictions about the performance of the two programs. The model assumes the informal credit market is segmented into a set of networks, each of which includes informal lenders and "connected" borrowers engaged in tight-knit economic and social relationships. The market also has a set of unconnected "floating" borrowers. Connected borrowers are more productive than floating borrowers because of exchange of information and help within networks. Lenders are better able to enforce repayment by borrowers within their network, so connected borrowers are more likely to repay loans from own-network lenders. Floaters have a higher default risk, and subsequently pay higher interest rates in the informal credit market. In the TRAIL scheme, an informal lender from one of the networks is chosen as the agent. The repayment-based commissions create a strong incentive for the agent to recommend own-network borrowers rather than borrowers outside his network. In contrast, GBL borrower groups are assortatively matched: both connected and unconnected borrower groups form. Since floating borrowers pay higher interest rates on the informal market and expect to default more often, groups of floating borrowers have a stronger motivation to form and apply for GBL loans. Hence the model predicts greater selectivity in TRAIL in favor of connected borrowers, implying both higher average productivity and lower default risk.

We test these predictions against the observed selection patterns. The TRAIL agent was significantly more likely to recommend borrowers from his own clientele and social group. On informal loans taken before the MFI introduced the lending schemes, GBL eligible borrowers (those that formed groups) paid almost 5 percentage points higher interest rates than households that did not form groups. In contrast, borrowers that the TRAIL agent recommended paid rates similar to those who he did not recommend, and recommended borrowers in the same economic network as the TRAIL agent paid 5 percentage points lower. Moreover, observed differences in production and incomes from potato cultivation are consistent with the prediction that own-network recommended borrowers were more productive than out-of-network borrowers in TRAIL, and that recommended TRAIL borrowers were more productive on average than self-selected GBL borrowers, though these differences were not statistically significant.

A few qualifications are in order. Owing to the relatively small scale of the intervention, we ignore any possible spillover effects of the programs to non-beneficiaries. Our focus is restricted to impacts on production and incomes; we do not examine impacts on consump-

end of the third year. 
tion, investment or measures of empowerment. We do not examine distributive impacts across landownership, caste or gender lines. These are relevant to any welfare analysis of TRAIL and GBL. And as stated earlier, we do not study possible roles played by a number of underlying channels that may have accounted for their differential performance, such as borrower incentives (individual liability in TRAIL versus the joint liability tax in GBL), control or social capital (vertical links in TRAIL versus horizontal links in GBL). We leave these questions for future work.

The paper is organized as follows. Section 2 presents the experimental design and data, followed by Section 3, which presents the main empirical results: impacts on total borrowing, acreage, output and value-added from the major crops, farm income and loan performance. Section 4 presents the main theoretical model of differences in selection between TRAIL and GBL. In Section 5 we test the predictions derived from the theoretical model against the observed selection patterns. Section 6 presents a set of robustness checks and sensitivity analysis and also contains a discussion of the financial sustainability of the two schemes. Section 7 concludes.

\section{Experimental Design and Data}

We collaborated with Shree Sanchari, a microfinance institution (MFI) based in Kolkata, to conduct a field experiment in the districts of Hugli and West Medinipur in the state of West Bengal, India. These districts are among the top producers of potatoes in West Bengal. The state itself produces about a third of all potatoes grown in India. The MFI introduced the TRAIL scheme in 24 randomly selected villages, and the GBL scheme in a separate set of 24 villages. To minimize spillovers, the experimental design ensured that each TRAIL village was at least 8 kilometers away from a GBL village. Prior to this project, the MFI had not operated in any of these villages. ${ }^{3}$

In both schemes, the MFI offered borrowers multiple cycles of loans of 4-month durations at an annual interest rate of $18 \%$. The first cycle loans were capped at Rupees 2000 (equivalent to approximately $\$ \mathrm{US} 40$ at the prevailing exchange rate), and were disbursed in October-November 2010, to coincide with the potato-planting season. Repayment was due in a single lump sum after 4 months. Upon full repayment, the borrower became eligible for a new loan which was 33 percent larger than the first, for another 4-month duration and at the same interest rate. In this way in each subsequent cycle successful borrowers became eligible for a 33 percent increase in loan size, with all other loan terms remaining unchanged. Those who repaid less than 50 percent of the repayment due were not

\footnotetext{
${ }^{3}$ In another 24 villages, the MFI implemented an alternative version of the agent intermediated lending scheme called GRAIL, where the agent was recommended by the village council or Gram Panchayat. Borrower selection and impacts of the GRAIL scheme will be analysed in future research. Sixty-eight of the total of 72 villages were also part of a sample drawn for a previous project conducted by a subset of the current authors (see Mitra, Mookherjee, Torero, and Visaria, 2014).
} 
allowed to borrow again. Those who repaid between 50 and 100 percent of the repayment amount were eligible to borrow 133 percent of the principal repaid. To facilitate credit access for post-harvest storage, borrowers were allowed to repay the loan in the form of potato "bonds" rather than cash, in which case the amount repaid was calculated at the prevailing price of potato bonds. ${ }^{4}$ Both schemes had an in-built index insurance scheme the required repayment would be revised downwards if revenue per acre for potatoes fell 25 percent below a three year average in the village, as assessed through a separate village survey. While the MFI told borrowers that these were agricultural loans, and the terms of the loans implicitly encouraged borrowers to use them for agriculture, borrowers were not required to report to the MFI the intended or actual use of the loan. ${ }^{5}$

It is worth considering how our intervention compares with other similar interventions (see the summary presented in Banerjee, Karlan, and Zinman, 2015, Table 1). The differences are summarized in Table 1. Apart from TRAIL borrower selection procedures, an important difference is in repayment frequency: loans were due in a single lumpsum at the end of 4 months in both TRAIL and GBL schemes, whereas repayment is due on weekly, bi-monthly or monthly schedules in the other studies. Many of the other loan features are comparable between TRAIL and GBL, and the other microcredit products. An important difference is in the scale of the program. We rationed loan offers to ten eligible borrowers in each village. In contrast, in most evaluations in the literature, the scale of the program was determined by the demand for the loan product: clusters (slums or villages) were randomly allocated to either the treatment or control groups and the MFI only operated in the treatment clusters. The impacts estimated in the latter combine selection and loan treatment effects, and are interpreted as the effects of entry of an MFI into a cluster on a representative member of an 'eligible' sub-population within that cluster, where loan take-up within this sub-population is entirely demand determined. In our context, loan treatment effects are conditional on being selected by the program to receive a loan offer, and measure the impacts relative to others who were equally eligible but did not receive the offer. ${ }^{6}$

\subsection{The Trader-Agent-Intermediated Lending (TRAIL) Scheme}

In the TRAIL villages, officials from the MFI consulted with prominent persons in the village to draw up a list of traders and business people who had at least 50 clients in the village, and had been in business in the village for at least three years. One person from the list was randomly chosen and offered the opportunity to become an agent. ${ }^{7}$ The agent was

\footnotetext{
${ }^{4}$ When potatoes are placed in cold storage, the storage facility issues receipts, also known as "bonds". These are traded by farmers and traders.

${ }^{5}$ However in our household surveys we did ask respondents to tell us the actual purpose of each loan they reported having taken.

${ }^{6}$ The loan treatment effects presented in Karlan and Zinman (2011) also control for selection; loan assignment was randomized among borrowers deemed marginally creditworthy by a credit scoring algorithm.

${ }^{7}$ The experimental protocol stated that if the person approached rejected the offer, the position would be offered to another randomly chosen person from the list. Officials from the MFI would go down the list in this manner until the position was filled. In practice, the first person offered the position accepted it in
} 
asked to recommend 30 village residents who owned no more than 1.5 acres of agricultural land, as potential borrowers. Our project officer and an official from the MFI conducted a lottery in the presence of village leaders to select 10 out of these 30 individuals, who were then offered the loan. Loan officers visited these randomly chosen individuals in their homes to explain the loan terms and disburse the loan if they accepted the offer.

At the beginning of Cycle 1, for each loan given to borrowers whom he recommended, the agent was required to deposit Rs 50 with Shree Sanchari. At the end of each loan cycle he received as commission $75 \%$ of the interest received on these loans. The deposit was refunded to the agent at the end of two years, in proportion to the loan repayment rates of his recommended borrowers. Agents were told their contract would be terminated at the end of any cycle in which 50\% of their recommended borrowers failed to repay. Agents were also promised an expenses-paid holiday at a local sea-side resort if they survived in the program for two years.

One could worry about possible abuse of power by agents. TRAIL agents could charge high interest rates (if permitted or through kickbacks), select unsuitable borrowers (high default risks, less productive individuals, wealthy individuals, cronies or persons willing to pay bribes), extract borrower benefits by manipulating other relationships, collude with borrowers (recommend non-repayment and divide up loan funds) or coerce borrowers to repay. The scheme therefore contained several features meant to limit agent discretion. The MFI lent to the client directly rather than through the agent; the agent could recommend only landless and marginal landowners (households owning $\leq 1.5$ acres), and the interest rate was fixed by the MFI and communicated clearly to all borrowers.

\subsection{The Group-based Lending (GBL) Scheme}

In the GBL villages, the MFI initiated operations in February-March 2010 by inviting residents to form 5-member groups, and then organizing bi-monthly meetings for each group, where each member was expected to deposit Rupees 50 per month into the group account. Of the groups that survived until October 15, 2010, two were randomly selected into the scheme through a public lottery. Each group member received a loan of Rupees 2,000 in Cycle 1, for a total of Rupees 10,000 for the entire group, with a four-month duration, payable in a single lump sum. All group members shared liability for the entire Rupees 10,000: if less than 50\% of the due amount was repaid in any cycle, all members were disqualified from future loans; otherwise the group was eligible for a new loan which was $33 \%$ larger than the previous loan. Bi-monthly group meetings continued throughout, in keeping with the MFI's standard protocol for joint liability lending.

every village. 


\subsection{Data and Descriptive Statistics}

Starting in December 2010, we collected household survey data from 50 households in each village at four-month intervals. This included information about household demographics, assets, landholding, cultivation, land use, agricultural input use, sale and storage of agricultural output, credit received and given, incomes, and economic relationships within the village. The household sample was composed of three sub-groups of villagers, all of whom owned at most 1.5 acres of land. In each village we included all 10 Treatment households: households that both were recommended for loans/formed groups (in TRAIL/GBL villages, respectively) and also were randomly selected to receive loans. We also included 10 Control 1 households: chosen randomly from those that were recommended/formed groups (in TRAIL/GBL respectively) but were not selected to receive loans. Finally, we included 30 households that were not recommended/did not form groups. These were chosen by first, purposively selecting households to ensure that all 24 sample households from the Mitra, Mookherjee, Torero, and Visaria (2014) study were included, and next, filling any remaining additional sample slots through a random draw of non-recommended/nonselected households from the village. ${ }^{8}$

We followed all sample households over a period of three years. Surveys were conducted every four months. Therefore all information on loans, inputs, production and labor market participation were collected every four months, which helps to minimize measurement error. We have zero attrition over the three years, and the survey respondent in each household remained the same through the different surveys. Panel A in Table 3 provides checks of balance for the randomization of villages into the TRAIL versus GBL categories. As can be seen, there were no significant differences in village-level characteristics across the two groups.

Within each category, Panel B checks the randomization of selected households into the Control 1 and Treatment groups. ${ }^{9}$ For most characteristics, there are only minor differences across households assigned to the Treatment or Control 1 arms. As the F-statistic shows, we cannot reject the joint hypothesis of no differences across Treatment and Control 1 households in either the TRAIL or GBL villages.

Table 4 describes credit market transactions that took place during September - December 2010 in all sample households that owned less than 1.5 acres of land. Since this was the planting season for potatoes, which is the crop with the highest working capital requirements in this region (as shown in Table 5, below), these data provide a picture of the

\footnotetext{
${ }^{8}$ The 24 households in the Mitra, Mookherjee, Torero, and Visaria (2014) study were a stratified (by land-size) random sample of all households that had cultivated potatoes in the year 2007.

${ }^{9}$ It is unlikely that our full sample of 50 households per village would be balanced across treatment groups, since both Treatment and Control 1 households were systematically selected into the sample by virtue of being recommended by the agent (TRAIL villages)/joining a group (GBL villages). In contrast, Control 2 households were selected by virtue of not being recommended, and form an unknown proportion of the population of households that the agent would not have wanted to recommend. Thus it is unclear how to re-weight these two groups to arrive at a representative sample of village households.
} 
main sources of agricultural credit, and characteristics of the loans. The sample households self-reported all borrowing, regardless of source or loan purpose. We present here data on all borrowing and borrowing for agricultural purposes. ${ }^{10}$ Note first that nearly 70 percent of sample households borrowed in this 4-month period. Informal lenders (traders and moneylenders) provided two-third of all agricultural credit and thus were the single most important lender category. Credit cooperatives provided about a quarter of the agricultural credit, but they loaned mainly to households with relatively larger landholdings. ${ }^{11}$

The average interest rate on loans from informal lenders is $26 \%$, substantially above the rate that Shree Sanchari charged on the program loans. The average duration of informal loans is 4 months, presumably reflecting the fact that agricultural cycles in this area are four months long. Only $1 \%$ of informal loans are secured by collateral. Cooperatives and government banks charge substantially lower interest rates and have longer average durations, but are much more likely to be collateralized, suggesting that they are unavailable to households with low assets. ${ }^{12}$

Table 5 describes the mean characteristics of the major categories of crops grown by sample farmers in the three years of data used in our analysis. Paddy is grown twice or three times a year, on an average of 0.47 acres of land. Potatoes and sesame are both winter crops planted only once a year, and the average farmer planted each on similar quantities of land: potatoes on 0.31 acres and sesame on 0.22 acres. A small subset of sample farmers grow a range of vegetables such as cauliflower, cabbage, gourd, chillies and lentils year-round at high profits, but on average this accounts for only 0.02 acres per year. As the table makes clear, potatoes are the major cash crop for the farmers in our sample: they account for a significant proportion of acreage, have the highest working capital needs, and generate the highest value added per acre.

\section{Empirical Analysis}

The two lending schemes that we examine in this paper differ in terms of how borrowers were selected. Therefore, when estimating and comparing the effects of the loans on borrowers, we account for the fact that selected households in the two schemes may have very different characteristics, not all of which may be observable to the researcher. To estimate

\footnotetext{
${ }^{10}$ Importantly, the data also include information on trade credit from input suppliers. Since we collected detailed data on input purchases, we are able to cross-check that all inputs purchased on credit are counted as loans.

${ }^{11}$ It is important to note that other MFIs had a very small share of the overall credit provided in these villages. This is indicative of low MFI penetration in these regions of India at the start of the intervention.

${ }^{12}$ In statistics not presented here, we find that informal lending becomes a progressively more important source of agricultural credit as household landholding decreases from 1.5 acres to zero. Landless households received $87 \%$ of their agricultural credit from informal lenders, and only $6 \%$ from cooperatives. Presumably this is because cooperatives require that the borrower posts collateral: nearly three quarters of cooperative loans were collateralized.
} 
the treatment effect associated with either of the two mechanisms, we rely on the fact that only a randomly chosen subset of the selected borrowers (recommended by the agent in the TRAIL villages or self-formed groups in the GBL villages) were offered the loans. Any difference between households that were recommended but were not offered the loan (Control 1 households) and those that were both recommended and offered the loans (Treatment households) must be caused by the loans. Similarly we can estimate the selection effect, which is given by the difference between the Control 1 and Control 2 households (those that were not recommended in the TRAIL villages or did not form groups in the GBL villages).

Our regression specification then takes the following form:

$$
\begin{aligned}
y_{i v} & =\beta_{0}+\beta_{1} \text { TRAIL }_{v}+\beta_{2}\left(\text { TRAIL }_{v} \times \text { Control } 1_{i v}\right)+\beta_{3}\left(\text { TRAIL }_{v} \times \text { Treatment }_{i v}\right) \\
& +\beta_{4}\left(\mathrm{GBL}_{v} \times \text { Control } 1_{i v}\right)+\beta_{5}\left(\mathrm{GBL}_{v} \times \text { Treatment }_{i v}\right)+\gamma \mathbf{X}_{i v}+\varepsilon_{i v}
\end{aligned}
$$

Here $y_{i v}$ denotes the outcome variable of interest for household $i$ in village $v$. The omitted category is the Control 2 group in GBL villages, so that $\beta_{2}$ is the selection effect in the TRAIL scheme, $\beta_{4}$ is the selection effect in the GBL scheme, $\beta_{3}-\beta_{2}$ is the treatment effect in the TRAIL scheme and $\beta_{5}-\beta_{4}$ is the treatment effect in the GBL scheme. ${ }^{13} \mathbf{X}_{i v}$ is a set of additional controls, including land owned by the households, two year dummies to control for secular changes over time and a dummy variable for whether the village received a separate intervention informing residents of the prevailing market price for potatoes. ${ }^{14}$

\subsection{Treatment effects on borrowing, cultivation and farm in- comes}

Tables 6, 7 and 8 present estimates of the treatment effects of the main outcomes of interest: borrowing (Table 6), cultivation and farm incomes from potatoes, the major cash crop (Panel A, Table 7), cultivation and farm incomes from the other crops (Panel B, Table 7) and total agricultural income (Table 8). All dependent variables pertain to yearly averages, where we estimate the impact averaging across the three years of the intervention. These treatment effects are computed from the regressions specified in equation (1).

When a large number of outcome variables is analyzed, it is possible that the null of no treatment effect is rejected by mere chance, even if the null is actually true. To correct

\footnotetext{
${ }^{13}$ All treatment effects presented in the tables below are intent-to-treat estimates because they compare the outcomes for households assigned to Treatment and Control 1 groups, regardless of actual take-up.

${ }^{14}$ This information intervention was undertaken for a separate project aimed at examining the effect of providing information about potato prices to farmers and is similar to the public information treatment described in Mitra, Mookherjee, Torero, and Visaria (2014). Villages were assigned to the information treatment randomly and orthogonally to the credit intervention that is the focus of this paper.
} 
for this, we follow Hochberg (1988) and compute a conservative p-value for an index of variables in a family of outcomes taken together (see Kling, Liebman, and Katz, 2007). ${ }^{15}$

\subsubsection{Effects on borrowing}

Table 6 presents the effects of the TRAIL and GBL schemes on how much households borrow for agricultural purposes. The TRAIL treatment caused overall borrowing to increase by Rs 5100 , which represents a $92 \%$ increase over the Rs 5548 mean borrowing by Control 1 households. In the GBL villages, the treatment caused overall borrowing to increase significantly by Rs 3701, which is also a $92 \%$ increase over the mean for the Control 1 households.

To check if the program loans crowded out loans from other sources, column 2 in Table 6 examines if the treatment caused a decrease in total borrowing for agricultural purposes through non-program loans. The treatment effects are small in magnitude and are not statistically significant for either TRAIL or GBL borrowers. Thus the program loans constitute a net addition to the agricultural borrowing of the treated households, consistent with the idea that our sample households face credit constraints in agriculture.

Looking at all borrowing outcomes taken together, we find that TRAIL loans caused a 0.24 standard deviation increase in household borrowing, which is significant even when we consider the more conservative Hochberg p-value that corrects for multiple hypothesis testing $(p-$ value $=0.025)$. However although GBL loans caused a 0.19 standard deviation increase in household borrowing, the effect is not statistically significant (Hochberg $p-$ value $=0.368)$.

\subsubsection{Effects on Cultivation and Farm Incomes}

Since the treatment caused total borrowing for agriculture to increase, one would expect it to have created real effects through increased agricultural activity. Since the loans were designed specifically to make it possible to finance the cultivation of potatoes, we first present the estimated effects on potato cultivation. These results are presented in Panel A of Table 7 show that there are statistically significant effects of the TRAIL loans on potato cultivation: a 7 percent increase in the likelihood of cultivating potatoes (column 1) and a 29 percent increase in acreage devoted to potato cultivation (column 2). TRAIL treatment households also spent more on inputs (column 4) and produced higher output (column 3;

\footnotetext{
${ }^{15}$ The variables are normalized by subtracting the mean in the control group and dividing by the standard deviation in the control group; the index is the simple average of the normalized variables. The p-value of the treatment effect for each index is adjusted as follows: the p-values for all indices are ranked in increasing order, and then each original p-value is multiplied by $(m-1+k)$, where $m$ is the number of indices and $k$ is the rank of the original p-value. If the resulting value is greater than 1 , we assign an adjusted p-value of $>0.999$.
} 
treatment effect is $27 \%$ of Control 1 mean). The net effect is a $29 \%$ increase in revenue and a $29 \%$ increase in value-added (column 6). Value-added is computed by subtracting from revenues only the costs of purchased or rented inputs and not the cost of self-provided inputs. However even when we impute a cost of family labor (using the average market wage rate for hired labor in the village, which gives us an upper bound for the shadow cost of family labor), the imputed net profit from potato cultivation in column 7 is Rs 1964, which is $37 \%$ of the mean for Control 1 households.

For GBL households the treatment effects are never statistically significant. The point estimates suggest that GBL treatment households increased the area under potato cultivation, and spent more on inputs, had larger output and earned higher revenue and value-added, but the treatment effects are small and estimated imprecisely. ${ }^{16}$

Looking at all outcomes related to potato production, we find that the TRAIL loans caused a 0.20 standard deviation increase (Hochberg $\mathrm{p}$-value $=0.002$ ) but the corresponding effect of GBL loans is statistically indistinguishable from zero (Hochberg p-value=0.759).

Panel B of Table 7 presents the effects on acreage and value-added from the other main crops: sesame, paddy and vegetables. Although TRAIL loans caused households to increase acreage devoted to all of these crops, there is no corresponding effect on value-added. There is no effect of GBL loans on either acreage or value-added.

Finally column 1 of Table 8 presents the treatment effects on total farm value-added aggregating across all four crop categories. Given the large share of potatoes in total cultivation, the TRAIL treatment effect on value-added from potatoes leads to a large, positive and statistically significant TRAIL treatment effect on overall farm value-added of $29 \%$ over the Control 1 mean. In contrast GBL loans had a negligible and statistically insignificant treatment effect on total farm income.

\subsection{Comparing Productivity of Selected TRAIL and GBL bor- rowers}

Were households recommended by TRAIL agents more productive than households that formed groups in GBL villages? To examine this question, we compare the rate of return on TRAIL and GBL loans, which is defined as the ratio of the treatment effect on value-added to the treatment effect on cultivation cost in TRAIL and GBL respectively. These are reported in columns 2 and 3 of Table 8, with standard errors computed by bootstrapping using 600 replications. The rate of return achieved by the TRAIL treatment households in potato was $115 \%$ and for total farm value-added was $127 \%$, both statistically significant at the $1 \%$ level. The rates of return achieved by the GBL treatment group were substantially

\footnotetext{
${ }^{16}$ The higher standard errors in GBL are consistent with the model that we will present in Section 4, which predicts that the GBL scheme encourages both low and high productivity borrowers to participate, unlike the TRAIL scheme.
} 
lower at $39 \%$ and $16 \%$ for value-added in potato and total farm value-added, which are also statistically significant. However for both potato and total farm value-added, the rate of return on TRAIL loans was significantly higher than that on GBL loans. ${ }^{17}$

\subsection{Loan Performance}

Although this increase in farm income is encouraging, outside an experimental setting MFIs would only adopt the TRAIL scheme if the repayment rates were comparable to those in standard microcredit. ${ }^{18}$ To examine loan performance, we use administrative data on takeup, continuation and repayment. Over the three years of the intervention, the repayment rate (conditional on eligibility) in the TRAIL and GBL schemes are both above 95 percent, in the range of the industry standard.

It is unclear whether to expect TRAIL loans to have higher or lower repayment rates than GBL loans: although TRAIL borrowers were more productive, GBL borrowers had the benefit of joint liability, so that even if their own projects failed, their group members might have repaid their loans on their behalf. Column 3 in Table 9 shows that the difference is not statistically significant. The take-up rate of loans in the two schemes is also a useful metric of the ex ante impact of these loans on borrower welfare. We define the take-up rate as the proportion of households that were offered the loan in Cycle 1 who took the loan in any cycle. We also compute the continuation rate, which is the proportion of those offered the loan in a particular cycle who took it. The continuation rate is jointly determined by past take-up, default (which would disqualify the household from participating in a subsequent cycle) and current take-up. As columns 1 and 2 show, by either definition, borrower participation was significantly higher in the TRAIL scheme than in the GBL scheme.

\section{Theoretical Model of Selection}

We have seen above that there were considerable differences in the performance of the TRAIL and GBL schemes. To understand what mechanisms could have generated these differences, we now develop a theoretical model of the informal credit market, focusing in particular on how borrowers are selected into the two schemes. The model is based on heterogeneity across borrowers and moral hazard in lending whereby borrowers can strategically default on their loans. Qualitatively similar results obtain in an adverse selection

\footnotetext{
${ }^{17}$ The higher productivity of TRAIL borrowers could have arisen either owing to intrinsic productivity differences between those selected for TRAIL and GBL loans respectively, or to help provided or monitoring by the agent as contrasted to group members, or to differences in borrower incentives owing to differences in liability. We cannot disentangle these different explanations.

${ }^{18}$ Field, Pande, Papp, and Rigol (2013) find that individual liability loans with an extended grace period generated increases in borrower incomes, but also increased default rates.
} 
setting, as shown in previous versions of this paper (see Maitra, Mitra, Mookherjee, Motta, and Visaria, 2014).

The village population is segmented into a collection of identical networks each containing $n$ connected borrowers and one or more lenders, and a group of floating borrowers who belong to no network. Network lenders have more frequent and intensive social and economic relationships with borrowers in their own network, which enable them to impose stronger sanctions on defaulting borrowers. This results in lower defaults in within-network lending. Lenders engage in Bertrand price competition with one another, both within and across networks. All lenders face a common cost of capital $\rho$.

Additional simplifying assumptions that we impose are the following: $(i)$ Production is not subject to any risk, but borrowers are subject to consumption need shocks that may cause them to default in some states of the world; (ii) borrowers have no collateral; (iii) limited liability constraints do not bind; $(i v)$ all parties are risk neutral; $(v)$ the only source of heterogeneity across borrowers pertain to whether or not they are connected and which network they belong to if they are connected; and (vi) loan contracts are stationary and exhibit no 'memory', with lenders imposing sanctions immediately following default and continuing to lend the same amount in the next period. The last assumption ensures we can use a static analysis and ignore dynamic complications.

Borrowers' projects are always successful but borrowers can default on their loans intentionally. We simplify the analysis by assuming that loan default rates depend only on whether a borrower is connected and whether the lender belongs to the same network, but not the loan details such as size or interest rate. This can be justified by an underlying model of default penalties and borrower shock distributions with suitable non-overlapping supports. ${ }^{19}$ The default risk is lowest $\left(1-p_{c}\right)$ for within-network or connected relationships, followed by loans given to floaters (who default with probability $1-p_{f}$ ). The highest default rates $1-p_{o}$ arise in cross-network loans. ${ }^{20}$ Here $p_{c}>p_{f}>p_{o}$.

A borrower with a given productivity parameter $g$ has a production function $g f(l)$, where $l$ denotes the scale of cultivation (which is assumed equal to loan size). Owing to help and information exchanged within networks, or differences in assets owned, connected borrowers are more productive than floaters: $g_{c}>g_{f}$, where subscripts represent the type of borrower.

\footnotetext{
${ }^{19}$ Penalties $P_{c}, P_{f}, P_{o}$ are imposed by lenders on connected, floater and other-network borrowers respectively in any period when they default. In addition, every borrower incurs an additional reputational cost or personal disutility $\theta$ of default, with an identical and independent distribution which takes possible values $\theta_{j}, j=1, \ldots, 4$, where $\theta_{j}<\theta_{j+1}$. A borrower of type $i=c, f$, o with default disutility $\theta$ defaults on a loan of size $L$ and interest rate $r$ if the repayment obligation $(1+r) L$ exceeds $P_{i}+\theta$. Possible realizations $\theta_{i}$ are spread out as follows given a relevant range of loan repayment values $R=(1+r) l$ : $\theta_{1}<R-P_{c}<\theta_{2}<R-P_{f}<\theta_{3}<R-P_{o}<\theta_{4}$ for all $R$ in this range. Then connected borrowers default only in state $\theta_{1}$, floaters in states $\theta_{1}, \theta_{2}$ and other-network borrowers in states $\theta_{1}, \theta_{2}, \theta_{3}$. These events have probabilities $1-p_{c}, 1-p_{f}, 1-p_{o}$ respectively.

${ }^{20}$ This can be justified by lower vulnerability of other-network borrowers to sanctions by a lender, compared to a floating borrower. The ordering of default risk between floaters and other-network borrowers is relatively inessential to our main results.
} 
The function $f$ is assumed to be strictly increasing, strictly concave, smooth and satisfies Inada conditions.

Use $l_{i}(r)$ to denote the Walrasian loan demand of type $i=c, f$ borrower at expected credit cost (denoted ECC) $r$, i.e., which maximizes $g_{i} f(l)-r l$. Let the maximized payoff be denoted $\Pi_{i}(r)$. For reasons explained below, we assume loan demands are interest inelastic, i.e., loan repayment $r l_{i}(r)$ is non-decreasing in $r$.

\subsection{The Informal Credit Market}

We start by describing how the informal market functions, prior to the MFI intervention. Lenders compete with one another in the credit market, and can make different contract offers to different borrowers. Besides their advantage with respect to enforcement of repayments ex post, a lender has a slight locational advantage over other lenders with regard to transactions with own-network borrowers: whenever the latter are indifferent between borrowing from different lenders they end up borrowing from their own-network lender.

The timing of offers in the informal credit market is as follows: at stage 1, lenders announce contract offers to every borrower in the village. At stage 2, each borrower accepts at most one offer, takes a loan of size $l$ at interest rate $r$ and produces $g_{i} f(l)$. At stage 3 , the borrowers default disutility $\theta$ is realized and they decide whether to repay or not.

Proposition 1 There is a unique equilibrium outcome in the informal market, in which connected types borrow loan size $l_{c}(\rho)$ from their own-network lender at interest rate $\rho / p_{c}$, while floaters borrow (from some lender) loan size $l_{f}(\rho)$ at interest rate $\rho / p_{f}$. All lenders earn zero profit.

Proof: Bertrand competition implies all lenders will offer to lend to floaters at a common interest rate $\frac{\rho}{p_{f}}$. Since the loan will be repaid with probability $p_{f}$, the expected cost of credit for the borrower will be $\rho$, and each floater will choose loan size $l_{f}(\rho)$.

Other-network lenders will offer to lend at interest rate $\frac{\rho}{p_{o}}$ to any given connected borrower, which will result in an expected cost of credit of $\rho$ for the borrower, and an expected payoff of $\Pi_{c}(\rho)$. Own-network lenders will have to offer the connected borrower at least this payoff, i.e., select $r, l$ to maximize $p_{c} r l-\rho l$ subject to $g_{c} f(l)-r l \geq \Pi_{c}(\rho)$. It is easy to verify that the best response of any own-network lender is to offer $l_{c}(\rho)$ at interest rate $\frac{\rho}{p_{c}}$.

Interest rates adjust perfectly for differences in default rates, ensuring an expected cost of lending for any given lender which does not vary with borrower type. Hence all lenders compete on an equal footing for each type of borrower. Loan sizes however vary across borrower types, with floaters demanding less credit owing to their lower productivity. 


\subsection{Entry of MFI}

Now consider an MFI that enters a village, using either TRAIL or GBL. TRAIL and GBL loans charge interest rate $r_{T}<\rho$. We simplify by assuming that credit limits do not bind: TRAIL and GBL borrowers can choose the size of their respective loans at the interest rate $r_{T}$. As it turns out, the credit limit was not binding for most borrowers during our intervention.

\subsubsection{GBL outcomes}

Suppose the MFI offers a GBL scheme. We simplify as in Besley and Coate (1995) or Ghatak (2000) and assume that group size is two; moreover utility is transferable within the group, so groups will maximize the sum of expected utilities of members.

GBL also involves additional costs of attending group meetings and meeting savings requirements. These will vary idiosyncratically across members. We assume these costs $c$ for any given member has a distribution function $G($.$) which is the same for all borrower$ groups, and has a support on $[0, \infty) .{ }^{21}$

Three different types of groups are possible: $(\mathrm{C}, \mathrm{C})$ with both members from the same network, $(\mathrm{F}, \mathrm{F})$ with two floating borrowers and $(\mathrm{C}, \mathrm{F})$ with one connected and one floating borrower. Cross-network groups are also possible, but as we shall see below, these are similar to (C, F). A member that fails to repay her loan makes the other member liable for it, and invites sanctions. We assume these sanctions operate in the same way as the sanctions imposed by the lenders, and generate the same kind of repayment behavior. Hence each member of a $(\mathrm{C}, \mathrm{C})$ group repays with probability $p_{c}{ }^{22}$ In both the $(\mathrm{F}, \mathrm{F})$ and the $(\mathrm{C}, \mathrm{F})$ groups, members cannot leverage the same social capital so each member defaults with probability $p_{f}$.

A loan given to a member of a $(\mathrm{C}, \mathrm{C})$ group is repaid with probability $1-\left(1-p_{c}\right)^{2}=$ $p_{c}\left(2-p_{c}\right)$. Therefore, the ECC for such a group member is $p_{c}\left(2-p_{c}\right) r_{T}$, lower than credit cost on the informal market. This difference in credit cost is an incentive to join a group, but has to be weighed against the cost $c$ of group meetings and savings. A member selects loan size $l_{c}\left(p_{c}\left(2-p_{c}\right) r_{T}\right)$. She receives expected utility $\Pi_{c}\left(p_{c}\left(2-p_{c}\right) r_{T}\right)$ net of the meeting costs $c$, as compared with the benefit $\Pi_{c}(\rho)$ on the informal market. The group survives from one period to the next with probability $p_{c}\left(2-p_{c}\right)$, and so each $(\mathrm{C}, \mathrm{C})$ group member's present value of utility is $W_{C C} \equiv \frac{\Pi_{c}\left(p_{c}\left(2-p_{c}\right) r_{T}\right)-c}{1-\delta p_{c}\left(2-p_{c}\right)}$.

\footnotetext{
${ }^{21}$ It is possible that these costs vary across network members and floaters, but it is unclear how they might vary. Floaters may be less wealthy than network members, so that savings requirements are more costly to them. On the other hand floaters may have lower opportunity costs of the time spent at group meetings. Since there is no compelling argument in either direction, we abstract from any difference.

${ }^{22}$ This is unless it is in the members' mutual interest to default more frequently, a matter discussed below.
} 
As Besley and Coate (1995) point out, a (C, C) group could default more often than we described above. For instance the members could agree to repay their loans with probability $p_{f}$ rather than $p_{c}$, and not punish each other for default following a $\theta_{2}$ shock to either member. This would lower their ECC to $p_{f}\left(2-p_{f}\right) r_{T}$. However it would also lower the probability that the group would survive to a subsequent cycle. If group members are patient enough ( $\delta$ is high), they choose to default less often. In what follows we assume that $\delta$ is large enough that a $(\mathrm{C}, \mathrm{C})$ group prefers to lower its default rate to the minimum feasible. ${ }^{23}$ Then the proportion of $(\mathrm{C}, \mathrm{C})$ groups that could potentially form is $G\left(\Pi_{c}\left(p_{c}\left(2-p_{c}\right) r_{T}\right)-\Pi_{c}(\rho)\right)$.

Analogously, an (F, F) group repays with probability $p_{f}\left(2-p_{f}\right)$, and face an ECC of $p_{f}\left(2-p_{f}\right) r_{T}$, which is lower than the ECC of a (C, C) group. Group members select loans of size $l_{f}\left(p_{f}\left(2-p_{f}\right) r_{T}\right)$ and earn a present value utility of $W_{F F} \equiv \frac{\Pi_{f}\left(p_{f}\left(2-p_{f}\right) r_{T}\right)-c}{1-\delta p_{f}\left(2-p_{f}\right)}$. The proportion of $(\mathrm{F}, \mathrm{F})$ groups that could potentially form is $G\left(\Pi_{f}\left(p_{f}\left(2-p_{f}\right) r_{T}\right)-\Pi_{f}(\rho)\right)$.

A mixed group (C, F) has weak sanctions within the group, and therefore repays with probability $p_{f}\left(2-p_{f}\right)$. Both members face an ECC of $p_{f}\left(2-p_{f}\right) r_{T}$. The $\mathrm{C}$ member achieves a present value utility of $\frac{\Pi_{c}\left(p_{f}\left(2-p_{f}\right) r_{T}\right)-c}{1-\delta p_{f}\left(2-p_{f}\right)}$, which is what a $(\mathrm{C}, \mathrm{C})$ group could achieve by each repaying with probability $p_{f}$ rather than $p_{c}$. By virtue of the assumption on $\delta$ above, this would be smaller than $V_{C C}$. On the other hand, the $\mathrm{F}$ member would receive the same present value utility as in a (F, F) group, so that there would be no incentives for mixed groups (or cross-network groups) to form. As in Ghatak (2000), assortative matching would obtain: either (C, C) or (F, F) groups would form.

The key point is that there is no screening mechanism to exclude the $(F, F)$ groups. In Ghatak (2000), the MFI is assumed to offer a menu of contracts which induces the highrisk groups to self-select into individual liability loans, and low risk groups into a joint liability loan. In practice MFIs rarely offer such an array of options to clients within any given village. Partly this owes to lack of knowledge of the exact distribution of borrower preferences in specific locations, besides pressures for uniformity in nature of loan products offered. With a single option involving a joint liability loan at interest rate $r_{T}$, as in our experiment, both types of groups would be induced to form with probabilities $\pi_{c} \equiv$ $G\left(\Pi_{c}\left(p_{c}\left(2-p_{c}\right) r_{T}\right)-\Pi_{c}(\rho)\right)$ and $\pi_{f} \equiv G\left(\Pi_{f}\left(p_{f}\left(2-p_{f}\right) r_{T}\right)-\Pi_{f}(\rho)\right)$ respectively. The ordering of these two probabilities could go either way, and will be more biased in favor of (F, F) groups if default risks vary more than productivity across the two types (i.e., the lower is $\frac{p_{f}}{p_{c}}$ is relative to $\left.\frac{g_{f}}{g_{c}}\right)$. In that case GBL will be characterized by adverse selection: those forming groups will pay above-average interest rates on the informal market.

\footnotetext{
${ }^{23}$ If this assumption is violated, it further causes repayment rates for TRAIL loans to be higher than for GBL loans.
} 


\subsubsection{TRAIL}

Now suppose the TRAIL scheme starts to operate in the village, and one of the network lenders is selected to be the agent. The agent receives a commission $K<1$ per rupee interest paid by the client. If the borrower defaults the agent imposes the same punishments as in the informal credit market, thereby generating the same default rates.

To start with, we presume (i) the agent cannot be bribed by borrowers to induce him to recommend them, and (ii) the agent is asked to recommend $L$ borrowers which is smaller than network size $n$. Later the consequences of relaxing these assumptions will be discussed.

We derive the agent's preference between recommending an own-network borrower, a floater and a cross-network borrower. Recommending type $i=c, f$ generates the following present value utility to the agent:

$$
V_{i} \equiv \frac{K p_{i} r_{T} l_{i}\left(p_{i} r_{T}\right)}{1-\delta p_{i}}
$$

while recommending type $o$ generates:

$$
V_{o} \equiv \frac{K p_{o} r_{T} l_{c}\left(p_{o} r_{T}\right)}{1-\delta p_{0}}
$$

Since loan demands are interest inelastic, the agent prefers to recommend own-network borrowers as they generate the highest expected commissions: $p_{c} r_{T} l_{c}\left(p_{c} r_{T}\right)$ exceeds both $p_{f} r_{T} l_{f}\left(p_{f} r_{T}\right)$ and $p_{o} r_{T} l_{c}\left(p_{o} r_{T}\right)$. Moreover, own network borrowers are less likely to default, generating a higher probability of continuation into the future.

The role of the inelasticity assumption is worth explaining here. If instead loans were highly interest elastic, the agent could prefer riskier borrowers as their ECC is lower owing to high default risk. This would cause them to choose loans of much larger size, by an extent that could outweigh the higher default risk. In our experiment the amounts borrowed by TRAIL and GBL borrowers were close to the credit limit, so there would be little prospect for risky borrowers to expand loan sizes by a huge margin. Hence the assumption is innocuous.

Given $L \leq n$, it follows the TRAIL agent will recommend only own-network borrowers, who will borrow $l_{c}\left(p_{c} r_{T}\right)$ and repay with probability $p_{c}$. In contrast, GBL will involve both kinds of groups: $(\mathrm{C}, \mathrm{C})$ and $(\mathrm{F}, \mathrm{F})$. It follows that a borrower's productivity and repayment risk in TRAIL will dominate GBL. Table 2 provides details of the TRAIL-GBL effects.

We now explain how results are modified if $L$ can exceed $n$ or in the presence of collusion.

If $L>n$, the agent will recommend all own-network borrowers, and still need to recommend some more. The remaining slots will be filled by either floaters or other-network borrowers. Either way, the borrower pool will be diluted. This is empirically relevant for us, as we do not find evidence of positive selection in TRAIL overall, but only within own clientele of the agent. The results are consistent with our model only if the agent is selecting floaters. 
Would the agent prefer to recommend floaters or other-network borrowers? There is a trade-off here, between productivity and risk. Ceteris paribus, other network borrowers are more productive and so select larger loans and repayment obligations, thereby generating larger commissions. On the other hand these borrowers are less likely to repay. The overall comparison can go either way. The agent prefers floaters if other-network borrowers are sufficiently riskier, or productivity differences are not too large. If loan demands exhibit constant elasticity: $l_{i}(r)=\left[\frac{g_{i}}{r}\right]^{\epsilon}$, then floaters are preferred if and only if:

$$
g_{c}^{\epsilon} \frac{p_{o}^{1-\epsilon}}{1-\delta p_{o}}<g_{f}^{\epsilon} \frac{p_{f}^{1-\epsilon}}{1-\delta p_{f}}
$$

If the agent can collude with borrowers, and appropriate fraction $\alpha$ of borrowers' surplus through an upfront lump-sum bribe, the expressions for the agent's payoff are modified as follows:

$$
\begin{gathered}
V_{i} \equiv \frac{K p_{i} r_{T} l_{i}\left(p_{i} r_{T}\right)+\alpha\left[\Pi_{i}\left(p_{i} r_{T}\right)-\Pi_{i}(\rho)\right]}{1-\delta p_{i}}, i=c, f \\
V_{o} \equiv \frac{K p_{o} r_{T} l_{c}\left(p_{o} r_{T}\right)+\alpha\left[\Pi_{c}\left(p_{0} r_{T}\right)-\Pi_{c}(\rho)\right]}{1-\delta p_{0}}
\end{gathered}
$$

If floaters derive greater benefits from the loans than connected borrowers, i.e., $\Pi_{f}\left(p_{f} r_{T}\right)-$ $\Pi_{f}(\rho)$ is larger than $\Pi_{c}\left(p_{c} r_{T}\right)-\Pi_{c}(\rho)$ (which cannot be ruled out, and is consistent with adverse selection in GBL) the floaters will be prepared to pay larger bribes, thereby tilting the balance towards floaters. Moreover, other network borrowers derive a larger per-period benefit than own network borrowers since they default more frequently: $\Pi_{c}\left(p_{o} r_{T}\right)-\Pi_{c}(\rho)$ is larger than $\Pi_{c}\left(p_{c} r_{T}\right)-\Pi_{c}(\rho)$. This will outweigh any difference in expected commissions between own and other-network borrowers if $\alpha$ exceeds the commission rate. ${ }^{24}$ They also obtain larger per period benefits compared with floaters: $\Pi_{c}\left(p_{o} r_{T}\right)-\Pi_{c}(\rho)$ is larger than $\Pi_{f}\left(p_{f} r_{T}\right)-\Pi_{f}(\rho)$. If $\alpha$ is large enough, the agent's expected per period benefit is higher for an other-network borrower compared to a floater. ${ }^{25}$ Counteracting these effects is the lower probability of continuation for other network borrowers and floaters. If the agent is very impatient ( $\delta$ is close to zero), he will select an other-network borrower. Hence the pattern of TRAIL selection cannot be predicted a priori when there is collusion and the agent extracts a sizeable portion of borrowers' surplus via bribes. Our results therefore depend on $\alpha$ being small enough.

\footnotetext{
${ }^{24}$ To see this note that $K p r_{T} l_{c}\left(p r_{T}\right)+\alpha\left[\Pi_{c}\left(p r_{T}\right)-\Pi_{c}(\rho)\right]$ is decreasing in $p$ as long as $\alpha \geq K$. The derivative of this expression wrt $p$ is $(K-\alpha) r_{T} l_{c}\left(p r_{T}\right)+K p r_{T}^{2} l_{c}^{\prime}\left(p r_{T}\right)$, which is negative if $K \leq \alpha$.

${ }^{25}$ To see this, note that $\Pi_{c}\left(p_{o} r_{T}\right)-\Pi_{f}\left(p_{f} r_{T}\right)=\left[p_{f} r_{T} l_{f}\left(p_{f} r_{T}\right)-p_{0} r_{T} l_{c}\left(p_{o} r_{T}\right)\right]+\left[g_{c} f\left(l_{c}\left(p_{o}\right) r_{T}\right)-\right.$ $g_{f} f\left(l_{f}\left(p_{f} r_{T}\right)\right]$. The first square bracket on the RHS is larger than the expected difference in commissions $K\left[p_{f} r_{T} l_{f}\left(p_{f} r_{T}\right)-p_{0} r_{T} l_{c}\left(p_{o} r_{T}\right)\right]$. The second square bracket is larger than $\Pi_{c}(\rho)-\Pi_{f}(\rho)=$ $\left\{g_{c} f\left(l_{c}(\rho)\right)-g_{f} f\left(l_{f}(\rho)\right)\right\}-\rho\left\{l_{c}(\rho)-l_{f}(\rho)\right\}$. Hence with $\alpha=1$, the expected per period benefit is highest for other network borrowers.
} 


\section{Selection Patterns in TRAIL and GBL}

We showed in Section 3.2 that TRAIL borrowers were more productive than GBL borrowers. In our theoretical model this occurs because TRAIL agents recommended households that belong to their own network, rather than floating borrowers. We now examine whether this is indeed the case in the data. In Table 10 we test if TRAIL agents exhibit a preference for recommending households that belonged to their network. We run the linear probability regression

$$
\text { Recommended }_{i v}=\alpha_{0}+\sum_{k=1}^{3} \beta_{k}(\text { Interacted with the agent in market } k)_{i v}+\mathbf{X}_{1 i v}+\varepsilon_{i v}
$$

on the sample of households owning at most 1.5 acres of cultivable land in TRAIL villages. The dependent variable takes the value 1 if the TRAIL agent recommended household $i$ in village $v$ for a loan, and 0 otherwise. ${ }^{26}$ On the right hand side we include three indicator variables for whether the household had interacted with the agent in the three years prior to the study - by buying inputs from, borrowing from or working for the agent. We also examine whether the agent was more likely to recommend borrowers belonging to different caste groups from themselves. We control for the household head's age, gender, educational status and primary occupation, household size, landholding, and receipt of government benefits.

In line with our prediction, we see in Table 10 that households that had borrowed from the agent in the past were 15 percentage points more likely to be recommended than households that had not interacted with the agent. We also find that scheduled caste agents were significantly more likely to recommend scheduled caste households; and high caste agents were significantly less likely to recommend scheduled caste households.

Consider now the interest rate that the households paid on informal loans they took prior to the intervention, as a measure of their inherent default risk. We examine how these varied depending on whether they were recommended by the agent, and whether they belonged to the same network:

$$
\begin{aligned}
r_{i v} & =\beta_{0}+\beta_{1} \text { Recommended }_{i v}+\beta_{2} \text { Interacted with agent }_{i v} \\
& +\beta_{3}\left(\operatorname{Recommended}_{i v} \times \text { Interacted with agent }_{i v}\right)+\gamma \mathbf{X}_{2 i v}+u_{i v}
\end{aligned}
$$

Here $r_{i v}$ is the average interest rate the household paid on informal loans they had taken in Cycle 1. The sample is restricted to households in TRAIL villages that owned at most 1.5 acres of land. The variable Interacted with agent is a summary indicator variable for whether the agent and the household had interacted in the input, credit or labor market in the three years prior to the study. The results presented in columns 1 and 2 of Table

\footnotetext{
${ }^{26}$ Thus both Treatment and Control 1 households receive a value of 1 , and Control 2 households have a value of zero.
} 
11 show that within the set of households whom the agent had interacted with in the past, those that he recommended had lower default risk: on average the interest rate they paid was 6.5 percentage points (or 34 percent) lower than the interest rate paid by households that were not recommended.

Note that the coefficient on the Recommended dummy in column 2 is positive but not statistically significant. This indicates that out-of-network borrowers recommended by the agent paid above average interest rates. The presence of out-of-network recommended borrowers corresponds to the case $L>n$ in our model, where the agent runs out of ownnetwork borrowers to recommend and so ends up recommending floaters who pay aboveaverage interest rates. The result in column 1 indicates that the interest rate deviations of the two groups of recommended borrowers (own-network and out-of-network) neutralized each other on average, so the average recommended borrower overall paid nearly the same interest rate as non-recommended borrowers.

Now turn to selection patterns in GBL. In column 3 of Table 11 we run the regression

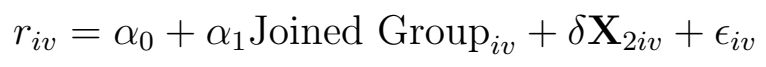

where Joined Group $i v$ takes the value 1 if household $i$ in GBL village $v$ was part of a group. These are the individuals that are eligible for a GBL loan. This regression is estimated on the sample of households that owned at most 1.5 acres of land in GBL villages using data from Cycle 1 only. The estimates show that before the intervention, households that formed GBL groups paid 4.5 percentage points (or 13 percent) higher interest rates in the informal market than those who did not form a group. The GBL scheme thus attracted borrowers whom local lenders perceived to be higher default risk than the rest of the village population. As explained in the previous section, such adverse selection is consistent with our model (pertaining to the case where default risks differ more relative to productivity between connected and floating borrowers).

The other question of interest is whether there is any evidence of productivity differences between selected and non-selected borrowers in either scheme. As (effective) informal credit cost does not vary across connected and floating borrowers, the model implies that if the former were more productive they would cultivate on a larger scale, take larger loans, apply more inputs and produce more output, controlling for landholding. Given the bias in TRAIL agent in favor of own-network borrowers, we would expect TRAIL recommended borrowers to apply more inputs and produce more potatoes than those not recommended. The first row of Table 12 shows that consistent with this prediction, borrowers who were recommended by the TRAIL agent but did not receive TRAIL loans allocated more land to potato cultivation, applied more inputs, produced more output and earned higher incomes than those not recommended. However these differences are not statistically significant. The model also predicts that corresponding selection effects in GBL may be negative, if it is biased sufficiently in favor of floaters. The point estimates of the GBL selection effects with regard to potato production, revenue and value added do turn out to be negative, but fail to be statistically significant. The last row shows that the point estimates of the 
TRAIL selection effects are always greater than the corresponding GBL selection effects, although these differences are not statistically significant either.

One possible reason why these differences are non-significant is that TRAIL agents did not have enough own network borrowers to recommend, so ended up recommending some floaters who were less productive than own-network borrowers. The model predicts that own-network recommended borrowers would experience higher treatment, rate of return and selection effects on production and incomes than out-of-network recommended borrowers. To test this, we run the following variant of equation (1) for TRAIL villages only:

$$
\begin{aligned}
y_{i v} & =\beta_{0}+\beta_{1} \text { Treatment }_{v}+\beta_{2} \text { Networked }_{i v}+\beta_{3}\left(\text { Treatment }_{i v} \times \text { Networked }_{i v}\right) \\
& +\beta_{4}\left(\text { Control } 1_{i v} \times \text { Networked }_{i v}\right)+\gamma \mathbf{X}_{i v}+\epsilon_{i v}
\end{aligned}
$$

where the dependent variables are the annual value-added and imputed profits from potato cultivation. We see in Table 13 that the point estimates of the treatment, rate of return and selection effects are indeed higher for the networked households. But these differences are not precisely enough estimated to be statistically significant.

\section{Robustness Checks and Sensitivity Analysis}

In this section we examine a number of ancillary issues that can potentially affect our assessment of the success of the TRAIL scheme. These include $(i)$ possible offsetting effects on non-farm incomes; ( $i$ i) time specific effects; ( $i i i)$ heterogeneity of treatment effects in value-added; $(i v)$ the possibility that borrower benefits might have been siphoned off by the TRAIL agent through higher input prices, lower output prices or higher interest rates on loans; and $(v)$ financial performance of the scheme.

\subsection{Effect on Non-farm Incomes}

We have already seen that TRAIL borrowers experienced a significant rise in their overall farm income (see column 1, Table 8). Did this increase in farm income come at the expense of non-farm incomes? Conversely, did the GBL loans have positive treatment effects on nonfarm incomes instead of agricultural incomes? The results in Table 14 suggest otherwise. We see positive but imprecisely estimated effects of the TRAIL loans on rental income, income from sales of animal products, labor income, reported business profits, current value of business and total household income from non-agricultural sources. The treatment effects of GBL loans are smaller and also estimated imprecisely. The point estimate of the GBL treatment effect on aggregate non-farm income is actually negative, while that for TRAIL is positive, although both are statistically indistinguishable from zero. 


\subsection{Year Specific Effects}

The TRAIL and GBL treatment effects on agricultural output that we presented in Table 7 are the average over the three years of the intervention. However, there might have been year-specific variations in the treatment effects. The production of cash crops usually involves high risk, partly because sale prices can fluctuate considerably from year to year. Alternatively, farmers might have learned gradually how best to utilise the additional working capital, so that treatment effects might become larger as the scheme continued longer. As Figure 1 shows, the TRAIL treatment effects on potato acreage and value-added from potato cultivation are positive and statistically significant in all three years. The effects are also similar across the three years, providing no evidence for learning over time. The GBL treatment effects are generally positive, but are imprecisely estimated. Note also that the GBL treatment effects on both variables increased over time, but the differences across years are statistically insignificant.

\subsection{Heterogeneity in Effects}

The average treatment effects presented in Table 7 could mask significant heterogeneity of the treatment effect: might they represent large effects for only a small fraction of treated subjects? Figure 2 presents the TRAIL and GBL treatment effects for value-added in potato cultivation and the associated $90 \%$ confidence interval at different quantiles of the distribution of value-added. While the GBL treatment effect is relatively stable across the different quantiles, the TRAIL treatment effect increases over the distribution. The positive average TRAIL treatment effect is driven by the positive and generally statistically significant TRAIL treatment effects for most of the top half of the value added distribution. Therefore the large average treatment effects of TRAIL are not driven by a few outliers.

\subsection{Extraction by Agent in Other Spheres of Interaction}

We showed above that the TRAIL agent was more likely to recommend borrowers from his own network. One may wonder whether he then extracted these benefits from the borrowers, either by requiring bribes before he recommended them, or demanding sidepayments, or by manipulating other transactions with them.

For obvious reasons we were unable to collect data on bribes or side-payments. However, we do have detailed data about input purchases from and output sale to the TRAIL agent, collected every four months. These can be used to test if the agent extracted rents from TRAIL borrowers through manipulation of these transactions. ${ }^{27}$

\footnotetext{
${ }^{27}$ A group of students from Boston University's Masters of Global Development Studies program did fieldwork and very helpful analysis addressing this question (see Ah-Tye, Bai, Blanco, Pheiffer, and Winata, 2013).
} 
In Table 15 we analyse input, output and credit transactions reported by sample households in TRAIL villages. Column 3 shows the mean incidence of such transactions for the Control 1 households. Note first that there is no evidence that recommended households interacted exclusively with the TRAIL agent in these markets. The first two rows of Panel A show that over the 3 years, only approximately $8 \%$ of input transactions by Control 1 households were with the agent, accounting for less than $2 \%$ of the value of inputs purchased. The top rows of Panel B show that $1 \%$ of output transactions of control 1 households were with the agent, representing less than $4 \%$ of the value of transactions, and the top two rows of Panel $\mathrm{C}$ show that $16 \%$ of Control 1 households borrowed from the agent, accounting for only $5 \%$ of their total borrowing.

We wish to examine if the TRAIL agent manipulated transactions to extract borrowers' benefits. He could have bought larger quantities from the borrowers at discounted prices or adjusted downward the price he paid for the output. He could have sold larger quantities of inputs at higher prices to the borrowers, or he could have charged higher interest rates on loans he gave to the borrowers. As column 1 of Panel B shows, TRAIL treatment has a significant effect only on the price at which borrowers purchased inorganic fertilizer and the rental rate on power tillers, and these effects are negative. If anything, the borrowers paid lower input prices to the agent, the very opposite of a siphoning off of benefits. Column 1 in Panel $\mathrm{C}$ shows that instead of borrowing more at higher interest rates, treatment borrowers were less likely to borrow from the agent during the three years of the experiment. The average interest rate charged by the agent also did not change.

Overall, we do not find evidence that the agent extracted side-payments from the borrowers by engaging in a larger volume of transactions, charging higher prices for inputs sold or paying lower prices for outputs purchased from the borrowers. It appears likely that the TRAIL treatment households retained control over the program benefits that accrued to them. These results also cast doubt on the hypothesis that the agent gave extra concessions on output sales or input purchases to TRAIL borrowers, compared to those that he recommended but did not receive TRAIL loans.

\subsection{Financial Performance}

Lending institutions usually evaluate loan programs in terms of their repayment rates, clientele size and administrative costs. We have shown that loan take-up rates were higher for the TRAIL than the GBL scheme and repayment rates were similar. In addition, it cost the MFI less to implement the TRAIL scheme than the GBL scheme. The per-month cost of operating the GBL scheme in a village was Rupees 1463, whereas the cost of running the TRAIL scheme was only Rupees 68 per village: a difference of almost Rupees 1400 per village. About 80 percent of this difference is explained by lower salary costs and transport expenses for loan officers, which followed from the absence of meetings in the 
TRAIL design. ${ }^{28}$

\section{Conclusion}

The problem of identifying creditworthy borrowers and ensuring repayment in the absence of collateral has made agricultural finance in developing countries notoriously costineffective for formal financial institutions. While microcredit has famously solved these problems by leveraging local information and enforcement, recent interventions have shown that they do not increase borrowers' incomes or production. In this study, we have demonstrated that it is possible to build on the key principles of microcredit and design a lending mechanism that targets productive poor farmers who earn high rates of return and repay the loans with high probability.

The trader-agent intermediated lending (TRAIL) scheme involved individual liability loans at below-market-average interest rates, durations that matched crop cycles of the most important cash crop in the region, and insurance against local yield and price shocks. The scheme was particularly successful at inducing selected beneficiaries to increase the cultivation and output of potatoes. This did not come at the cost of reduced income from any other source that we measured. ${ }^{29}$ We explained this result in terms of the underlying selection patterns: TRAIL agents recommended households from among their own networks that they knew were low-risk borrowers and had high productivity. The GBL scheme employed the traditional group-based micro-finance approach to borrower selection, and did not generate comparable effects on farm outcomes. We argue this is because both high and low productivity households participated in the GBL scheme. However, possibly due to the joint liability incentive to repay on behalf of defaulting group-members, the GBL loans also had high repayment rates. Loan take-up rates were higher in the TRAIL scheme, suggesting higher $e x$ ante effects on borrower welfare. We found no evidence that TRAIL agents siphoned off the benefits of recommended or treated borrowers by manipulating other economic transactions with them. TRAIL also achieved economies in administrative costs, owing to the reduced monitoring or other selection responsibilites borne by loan officers. The absence of mandatory group meetings, savings requirements, or the burden of joint liability also likely lowered the costs incurred by borrowers in participating in the scheme.

Our paper contributes to the policy debate on ways to promote financial inclusion of the rural poor in the developing world. Various countries have attempted to expand financial

\footnotetext{
${ }^{28}$ While the agent received a commission equal to $75 \%$ of the interest payment received from borrowers he had recommended, the MFI also retained $75 \%$ of the interest payment received from GBL borrowers. Therefore the difference in administrative costs reported here comes from the lower outlays required for loan officers' salaries and transport.

${ }^{29}$ The TRAIL treatment effects are consistently statistically significant and the GBL treatment effects are not. However, since the GBL treatment effects are highly imprecise, the differences between the TRAIL and GBL treatment effects generally turn out to be statistically insignificant.
} 
services in rural areas by employing local agents, but with limited success. ${ }^{30}$ The TRAIL scheme is also related to a lending approach that India's central bank has been promoting recently, where "banking facilitators" are recruited from within the local communities to select and monitor borrowers on behalf of formal banks (Srinivasan, 2008). To our knowledge no rigorous evaluation of that approach has been carried out so far. The findings from our study could inform policymakers and central bank officials involved in the design of that scheme.

A number of issues need further analysis. First, any analysis of welfare implications of the TRAIL and GBL schemes would require an analysis of distributive impacts and the impacts on household consumption, investment, health and child welfare. We also do not examine whether different landowning classes, castes or genders were affected differently. Second, we do not attempt to provide any estimates of effects at the village level, or general equilibrium effects of the schemes. This is because by design only 10 households in the village were offered the loan, so we expect negligible spillover effects. ${ }^{31}$ Third, there are questions concerning how to scale up TRAIL to a larger set of villages or more borrowers per village, and the extent to which this may dilute the performance of the scheme. Finally, we need to understand better the mechanisms driving our results. In addition to selecting good borrowers, do agents play an important role by monitoring borrowers or providing them help or useful skills? Our subsequent research currently underway is addressing these issues.

\section{References}

Ah-Tye, T., O. Bai, J. Blanco, C. Pheiffer, And S. Winata (2013): "The Effect of Social and Economic Ties on Loan Repayment in Agent-Intermediated Lending in West Bengal, India," Master's thesis, Boston University.

Attanasio, O., B. Augsburg, R. D. Haas, E. Fitzsimons, and H. Harmgart (2011): "Group Lending or Individual Lending? Evidence from a Randomised Field Experiment in Mongolia," Mimeo, IFS.

BanerJee, A. V. (2013): "Microcredit Under the Microscope: What Have We Learned in the Past Two Decades, and What Do We Need to Know?," Annual Review of Economics, 5, 487 - 519.

Banerjee, A. V., D. Karlan, And J. Zinman (2015): "Six Randomized Evaluations of Microcredit: Introduction and Further Steps," American Economic Journal: Applied Economics, 7(1), 1 - 21.

Besley, T., AND S. CoAte (1995): "Group lending, repayment incentives and social collateral," Journal of Development Economics, 46(1), 1 - 18.

\footnotetext{
${ }^{30}$ Agents have been employed to intermediate financial services in Thailand (Onchan, 1992), Philippines (Floro and Ray, 1997), Bangladesh (Maloney and Ahmad, 1988), Malaysia (Wells, 1978), Indonesia (Fuentes, 1996) and Senegal (Warning and Sadoulet, 1998).

${ }^{31}$ In many other studies of the impact of microcredit programs, all households in the treatment areas (slums or villages) could participate.
} 
Feigenberg, B., E. Field, And R. Pande (2013): "The Economic Returns to Social Interaction: Experimental Evidence from Microfinance," Review of Economic Studies, 80(4), 1459 - 1483.

Field, E., R. Pande, J. Papp, And N. Rigol (2013): "Does the Classic Microfinance Model Discourage Entrepreneurship Among the Poor? Experimental Evidence from India," American Economic Review, $103(6), 2196-2226$.

Fischer, G. (2013): “Contract Structure, Risk Sharing and Investment Choice," Econometrica, 81(3), $883-939$.

Floro, M. S., AND D. RAY (1997): "Vertical Links Between Formal and Informal Financial Institutions," Review of Development Economics, 1(1), $34-56$.

Fuentes, G. (1996): "The Use of Village Agents in Rural Credit Delivery," Journal of Development Studies, 33(2), $188-209$.

Ghatak, M. (2000): "Screening by the company you keep: joint liability lending and the peer selection effect," Economic Journal, 110(465), $601-631$.

Giné, X., AND D. Karlan (2014): "Group versus individual liability: Long-term evidence from Philippine microcredit lending groups," Journal of Development Economics, 107, $65-83$.

Hochberg, Y. (1988): "A sharper Bonferroni procedure for multiple tests of significance," Biometrika, $75(4), 800-802$.

Kaboski, J. P., AND R. M. Townsend (2011): "A structural evaluation of a large-scale quasiexperimental microfinance initiative," Econometrica, 79(5), 1357-1401.

Karlan, D., And J. Zinman (2011): "Microcredit in Theory and Practice: Using Randomized Credit Scoring for Impact Evaluation," Science, 332(6035), 1278 - 1284.

Kling, J. R., J. B. Liebman, And L. F. Katz (2007): "Experimental Analysis of Neighborhood Effects," Econometrica, 75, $83-119$.

Maitra, P., S. Mitra, D. Mookherjee, A. Motta, And S. Visaria (2014): "Agent Intermediated Lending: A New Approach to Microfinance," Discussion paper, Mimeo, Boston University.

Maloney, C., And A. B. Ahmad (1988): Rural Savings and Credit in Bangladesh. University Press Ltd., Dhaka Bangladesh.

Mitra, S., D. Mookherjee, M. Torero, and S. Visaria (2014): "Asymmetric Information and Middleman Margins: An Experiment with West Bengal Potato Farmers," Discussion paper, Mimeo, Hong Kong University of Science and Technology.

Onchan, T. (1992): "Informal Rural Finance in Thailand," in Informal Finance in Low-Income Countries, ed. by D. W. Adams, and D. Fitchett. Westview Press, Boulder, CO.

Srinivasan, N. (2008): Microfinance India. State of the Sector Report. SAGE.

Warning, M., And E. Sadoulet (1998): "The Performance of Village Intermediaries in Rural Credit Delivery under Changing Penalty Regimes: Evidence from Senegal," Journal of Development Studies, $35(1), 115-138$.

Wells, R. J. G. (1978): "An Input Credit Programme for Small Farmers in West Malaysia," Journal of Administration Overseas, 17, 4- 16. 
Table 1: Terms of TRAIL and GBL loans to other interventions

\begin{tabular}{|c|c|c|c|}
\hline & $\begin{array}{l}\text { TRAIL } \\
\text { (1) }\end{array}$ & $\begin{array}{l}\text { GBL } \\
(2)\end{array}$ & $\begin{array}{c}\text { Summary: Six evaluations } \\
\text { (Banerjee, Karlan, and Zinman, 2015, Table 1) } \\
\text { (3) }\end{array}$ \\
\hline Liability & Individual & Group (Joint) & Group (4), Individual (1), Both (1) \\
\hline Interest Rate & $18 \%$ APR & $18 \%$ APR & $\begin{array}{c}12-27 \% \text { APR } \\
(\text { Mexico }=110 \% \text { APR })\end{array}$ \\
\hline Market Interest Rate & $24 \%$ APR & $24 \%$ APR & $\begin{array}{c}16-47 \% \text { APR } \\
(\text { Mexico }=145 \% \text { APR })\end{array}$ \\
\hline Loan Length & 4 months & 4 months & $3-18$ months \\
\hline Repayment Frequency & 4 months & 4 months & Weekly/Bi-monthly/Monthly \\
\hline Group Size & - & 5 & $3-50$ \\
\hline Collateralized & No & No & Yes (3), No (3) \\
\hline Dynamic Incentives & Yes & Yes & Yes \\
\hline
\end{tabular}

Notes

Columns 1 and 2 summarize the terms of the TRAIL and GBL loans; Column 3 summarizes the results presented in Table 1 of Banerjee, Karlan, and Zinman (2015). 
Table 2: Predictions of TRAIL, GBL Effects, assuming no collusion and $L \leq n$

\begin{tabular}{|c|c|c|c|c|c|}
\hline Treatment & & $\begin{array}{c}\text { Composition } \\
\mathrm{C}=\text { connected } \\
\mathrm{F}=\text { floaters }\end{array}$ & $\begin{array}{c}\text { Observed } \\
\text { Interest rate }\end{array}$ & $\begin{array}{l}\text { Repayment } \\
\text { Rate }\end{array}$ & $\begin{array}{c}\text { Loan/Cultivation } \\
\text { Scale }\end{array}$ \\
\hline TRAIL & $\begin{array}{l}\text { Treatment } \\
\text { Control } 1\end{array}$ & $\begin{array}{l}\mathrm{C} \\
\mathrm{C}\end{array}$ & $\begin{array}{l}r_{T} \\
\frac{\rho}{p_{c}}\end{array}$ & $\begin{array}{l}p_{c} \\
p_{c}\end{array}$ & $\begin{array}{l}l_{c}\left(p_{c} r_{T}\right) \\
\quad l_{c}(\rho)\end{array}$ \\
\hline & Control 2 & $\mathrm{C}, \mathrm{F}$ & $\frac{\rho}{p_{c}}, \frac{\rho}{p_{f}}$ & $p_{c}, p_{f}$ & $l_{c}(\rho), l_{f}(\rho)$ \\
\hline GBL & $\begin{array}{l}\text { Treatment } \\
\text { Control } 1 \\
\text { Control } 2\end{array}$ & $\begin{array}{l}\mathrm{CC}, \mathrm{FF} \\
\mathrm{CC}, \mathrm{FF} \\
\mathrm{C}, \mathrm{F}\end{array}$ & $\begin{array}{l}\frac{r_{T}}{\frac{\rho}{p_{c}}}, \frac{\rho}{p_{f}} \\
\frac{\rho}{p_{c}}, \frac{\rho}{p_{f}}\end{array}$ & $\begin{array}{c}p_{c}\left(2-p_{c}\right), p_{f}\left(2-p_{f}\right) \\
p_{c}, p_{f} \\
p_{c}, p_{f}\end{array}$ & $\begin{array}{c}l_{c}\left(p_{c}\left(2-p_{c}\right) r_{T}\right), l_{f}\left(p_{f}\left(2-p_{f}\right) r_{T}\right) \\
l_{c}(\rho), l_{f}(\rho) \\
l_{c}(\rho), l_{f}(\rho)\end{array}$ \\
\hline
\end{tabular}


Table 3: Randomization

Panel A: Village Level Differences

TRAIL GBL Difference

TRAIL - GBL

\begin{tabular}{lccc}
\hline & & & \\
Number of households & 297.59 & 388.50 & -90.91 \\
& $(48.06)$ & $(80.36)$ & \\
Percent households electrified & 0.60 & 0.59 & 0.01 \\
& $(0.06)$ & $(0.05)$ & \\
Has primary school & 0.77 & 0.79 & -0.02 \\
& $(0.09)$ & $(0.08)$ & \\
Has primary health centre & 0.27 & 0.21 & 0.06 \\
Has bank branch & $(0.10)$ & $(0.08)$ & -0.03 \\
Has pucca road & 0.14 & 0.17 & -0.14 \\
& $(0.07)$ & $(0.08)$ & \\
& 0.27 & 0.42 & \\
\hline
\end{tabular}

Panel B: Household Level Differences

TRAIL

Treatment Control 1

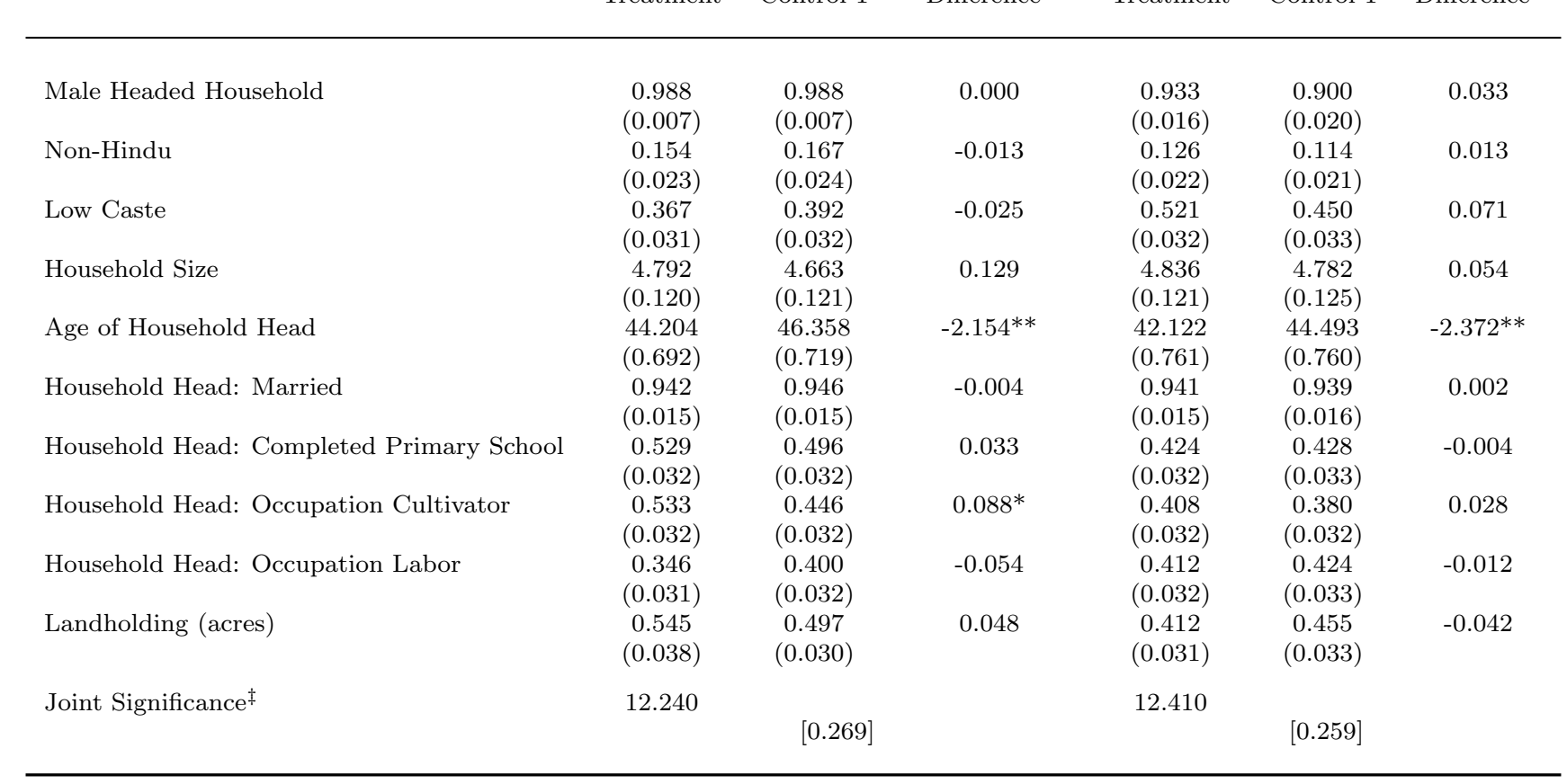

Notes:

Panel A uses village census data collected in 2007-2008. In Panel B the sample is restricted to recommended/selected (Treatment and Control 1) households in TRAIL and GBL villages. Standard errors are in parentheses. The p-value for the test of joint significance of all variables in explaining assignment to treatment is in square brackets. ${ }^{\ddagger}: \chi^{2}(12)$. ${ }^{\dagger}:$ Difference $=$ Treatment Control 1. ${ }^{* * *}: p<0.01,{ }^{* *}: p<0.05,{ }^{*}: p<0.1$. 
Table 4: Credit Market Characteristics (before experiment)

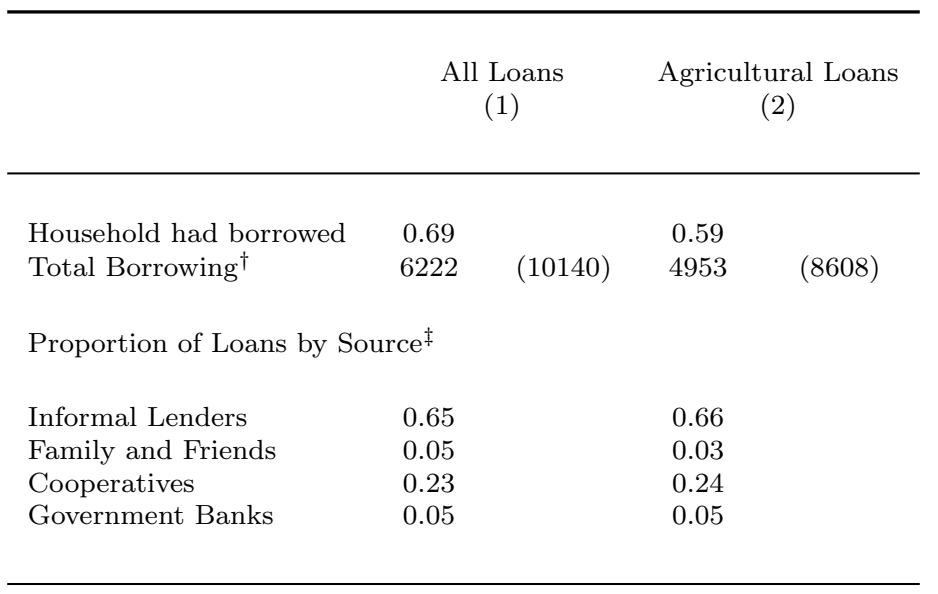

Annualized Interest Rate by Source (percent)

$\begin{array}{lcccc}\text { Informal Lenders } & 26.57 & (24.14) & 26.36 & (24.51) \\ \text { Family and Friends } & 20.53 & (15.09) & 19.84 & (16.32) \\ \text { Cooperatives } & 15.41 & (3.07) & 15.62 & (3.15) \\ \text { Government Banks } & 11.91 & (4.30) & 11.83 & (4.65)\end{array}$

Duration by Source (days)

Informal Lenders $\quad 123.63 \quad(27.54) \quad 122.52 \quad(20.29)$

Family and Friends $\quad 168.92 \quad(103.61) \quad 174.13 \quad$ (101.31)

$\begin{array}{llll}\text { Cooperatives } & 323.53 & (91.19) & 320.19\end{array}$

Government Banks $\quad 299.67 \quad(108.95) \quad 300.35 \quad$ (108.74)

Proportion of Loans Collateralized by Source

$\begin{array}{lll}\text { Informal Lenders } & 0.01 & 0.01 \\ \text { Family and Friends } & 0.02 & 0.07 \\ \text { Cooperatives } & 0.73 & 0.77 \\ \text { Government Banks } & 0.77 & 0.83\end{array}$

Notes:

Statistics are reported for all sample households in TRAIL and GBL villages (with at most 1.5 acres of land). All loan characteristics are summarized for loans taken by the household in Cycle 1. Program loans are not included. For the interest rate summary statistics loans where the principal amount is reported equal to the repayment amount are not included.

$\dagger$ : Total borrowing $=0$ for households that do not borrow.

¥: Proportion of loans in terms of value of loans at the household level. All proportions are computed only over households that borrow. Standard deviations are in parentheses. 
Table 5: Selected Crop Characteristics

\begin{tabular}{lccc}
\hline & $\begin{array}{c}\text { Sesame } \\
(1)\end{array}$ & $\begin{array}{c}\text { Paddy } \\
(2)\end{array}$ & $\begin{array}{c}\text { Potatoes } \\
(3)\end{array}$ \\
& & & \\
\hline & & & \\
Cultivate the crop (\%) & 0.49 & 0.69 & 0.64 \\
& $(0.006)$ & $(0.006)$ & $(0.006)$ \\
Acreage (acres) & 0.22 & 0.47 & 0.31 \\
& $(0.004)$ & $(0.006)$ & $(0.005)$ \\
Harvested quantity (kg) & 141 & 1175 & 5302 \\
& $(2.53)$ & $(16.12)$ & $(75.90)$ \\
Cost of production (Rs) & 341 & 3012 & 7731 \\
& $(8.08)$ & $(51.95)$ & $(138.57)$ \\
Price (Rs/kg) & 31 & 10 & 5 \\
& $(0.19)$ & $(0.09)$ & $(0.03)$ \\
Revenue (Rs) & 1667 & 5554 & 13726 \\
& $(37.45)$ & $(97.69)$ & $(248.6)$ \\
Value added (Rs) & 1325 & 2598 & 5938 \\
& $(32.85)$ & $(67.12)$ & $(145.82)$ \\
Value added per acre (Rs/acre) & 6349 & 6568 & 17777 \\
& $(84.23)$ & $(113.42)$ & $(282.92)$ \\
& & & \\
\hline
\end{tabular}

Notes:

Statistics are annual averages over the 3-year study period, reported for all sample households in TRAIL and GBL villages (with at most 1.5 acres of land). Standard errors are in parentheses. 
Table 6: Program Impacts: Treatment Effects on Total Borrowing

\begin{tabular}{lccc}
\hline & $\begin{array}{c}\text { All Loans } \\
(\text { Rupees }) \\
(1)\end{array}$ & $\begin{array}{c}\text { Non Program Loans } \\
(\text { Rupees }) \\
(2)\end{array}$ & $\begin{array}{c}\text { Index of dependent } \\
\text { variables }^{\amalg} \\
(3)\end{array}$ \\
\hline TRAIL Treatment & $\begin{array}{c}5101^{* * *} \\
(1032)\end{array}$ & -287 & 0.242 \\
Hochberg p-value & & 621 & $(0.082)$ \\
Mean Control 1 & 5548 & 5548 & 0.025 \\
\% Effect & 91.944 & -5.177 & 0.176 \\
\hline & & & $(0.092)$ \\
GBL Treatment & $3701^{* * *}$ & -196 & 0.368 \\
Hochberg p-value & $(1079)$ & $(766.4)$ & \\
Mean Control 1 & 4039 & & 6,210 \\
\% Effect & 91.632 & 4039 & \\
\hline & & -4.860 & \\
Sample Size & 6,210 & 6,210 & \\
\hline
\end{tabular}

Notes:

The regressions are run on household-year level data for all sample households (with at most 1.5 acres of land). Regression specification follows equation (1) in the text. $\amalg$ : In column 3 the dependent variable is an index of z-scores of the outcome variables in the panel; the p-values for treatment effects in this column are computed according to Hochberg (1988)'s step-up method to control for the family-weighted error rate across all index outcomes. ${ }^{\dagger}$ : Non-Program loans refer to loans from sources other than the TRAIL/GBL loan scheme. Standard errors in parentheses are clustered at the village level. ${ }^{* * *}: p<0.01,{ }^{* *}: p<0.05,{ }^{*}: p<0.1$. The complete regression results are in Table A-1. 


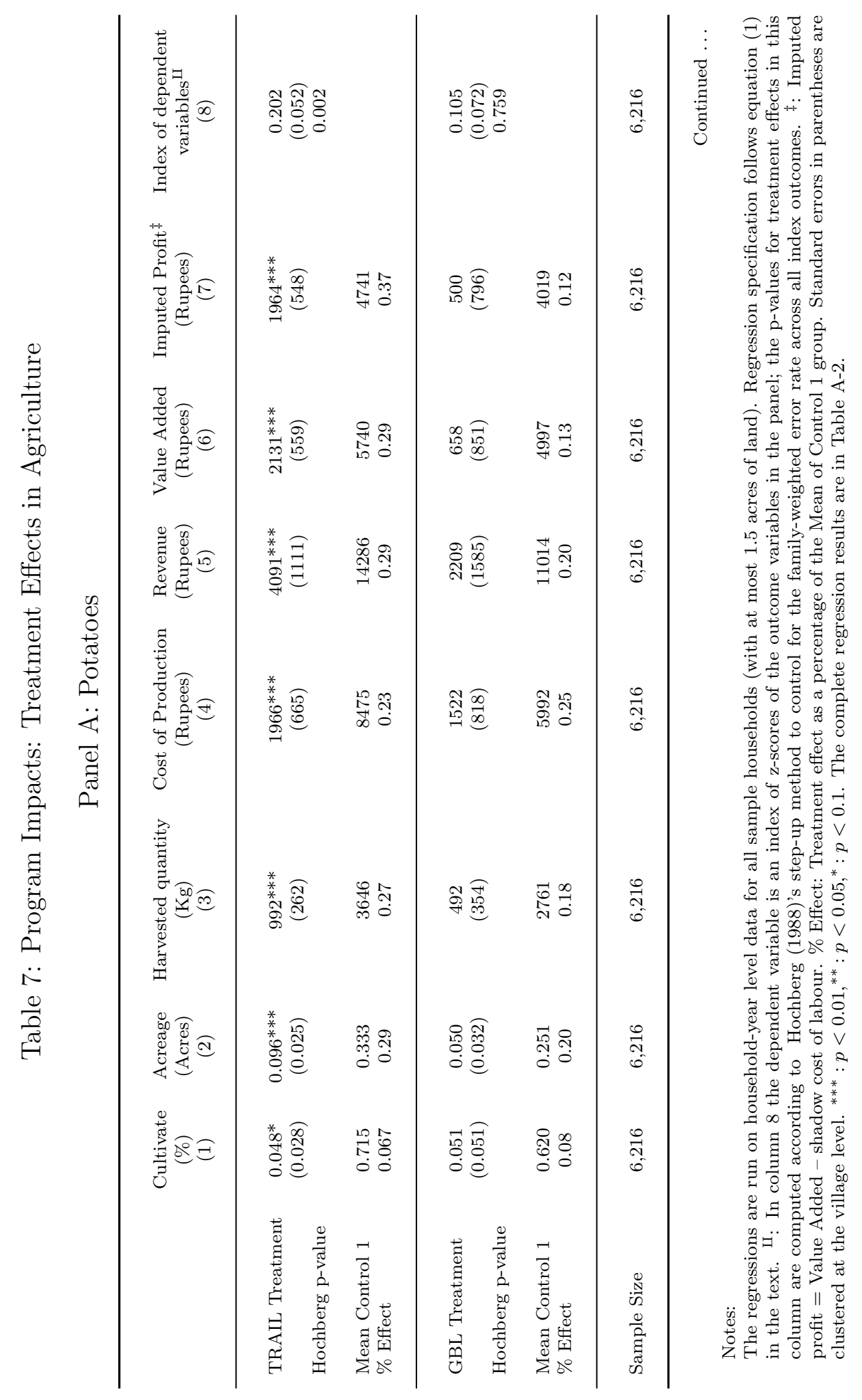




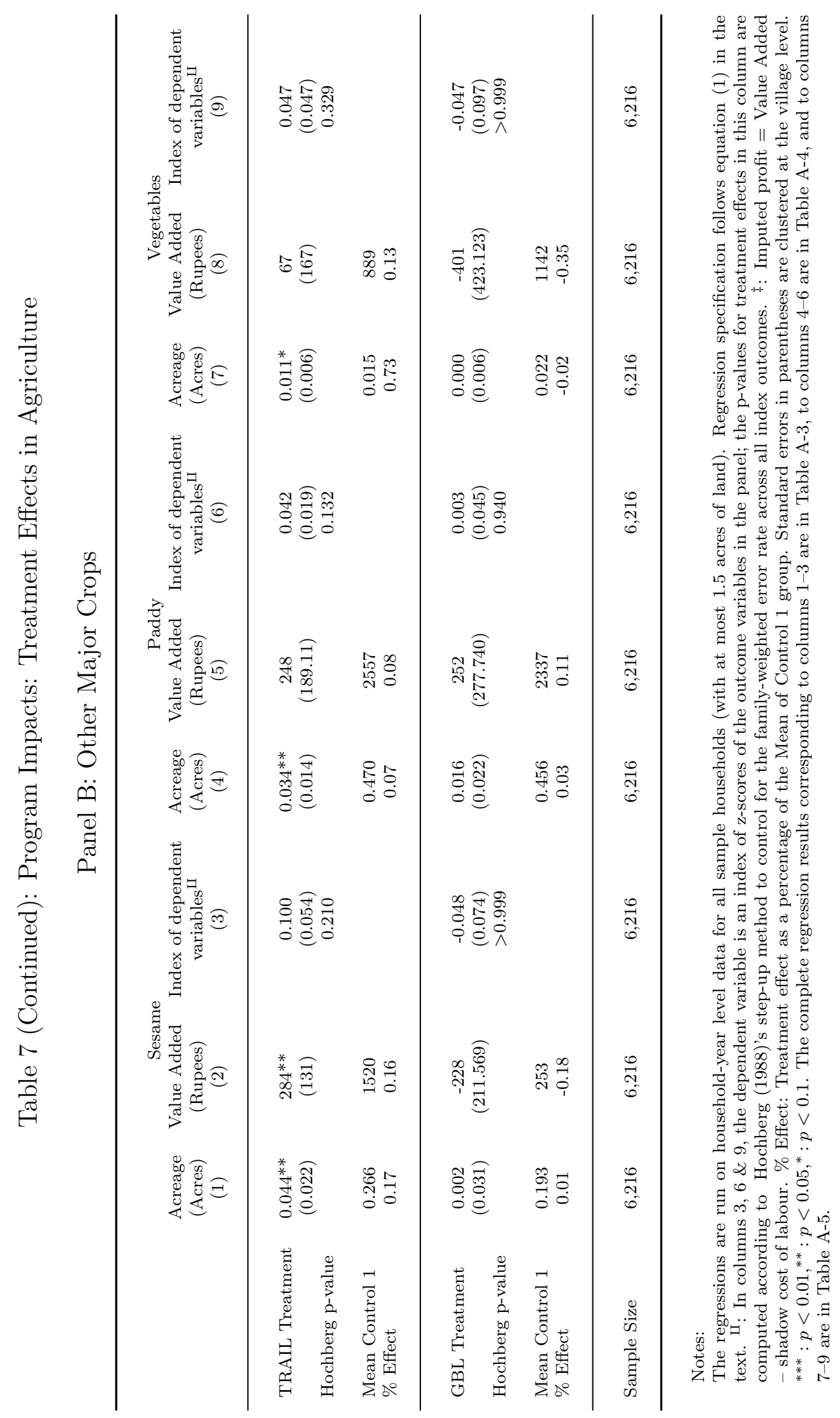


Table 8: Program Impacts: Effects on Farm Value Added and Rates of Return

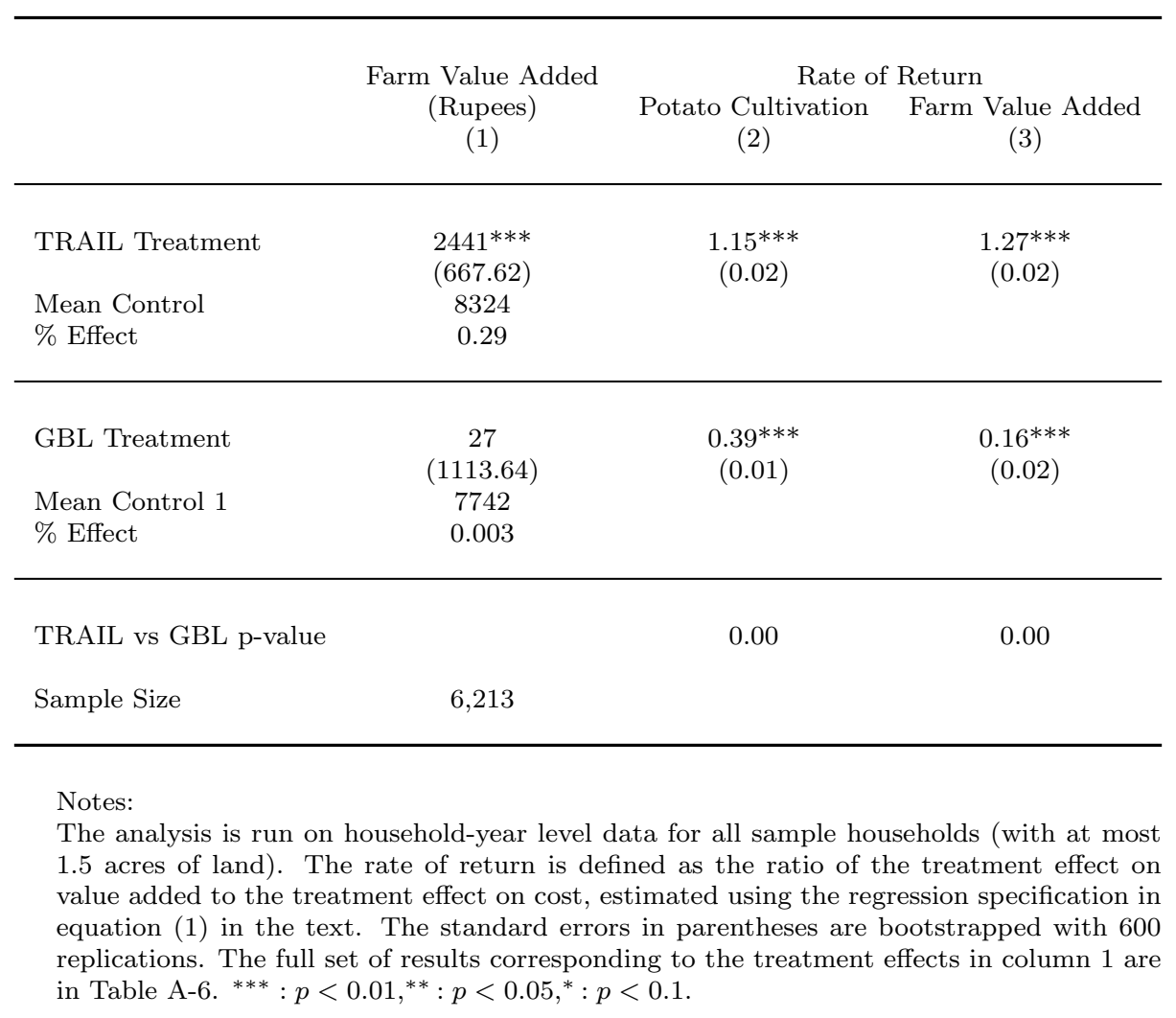


Table 9: Loan Performance

\begin{tabular}{lccc}
\hline & $\begin{array}{c}\text { Takeup } \\
(1)\end{array}$ & $\begin{array}{c}\text { Continuation } \\
(2)\end{array}$ & $\begin{array}{c}\text { Repayment } \\
(3)\end{array}$ \\
\hline \multirow{3}{*}{ TRAIL } & $\begin{array}{c}0.112^{* * *} \\
(0.014)\end{array}$ & $\begin{array}{c}0.112^{* * *} \\
(0.014)\end{array}$ & $\begin{array}{c}0.008 \\
(0.008)\end{array}$ \\
& $0.820^{* * *}$ & $0.823^{* * *}$ & $\begin{array}{c}1.006^{* * *} \\
\text { Constant } \\
\end{array}$ \\
& $(0.018)$ & $(0.018)$ & $(0.005)$ \\
\hline \multirow{3}{*}{ Mean GBL } & 0.694 & 0.747 & 0.956 \\
Sample Size & 3,512 & 3,226 & 2,406 \\
\hline
\end{tabular}

Notes:

The sample consists of household-cycle level observations of treatment households in TRAIL and GBL villages. The dependent variable in column (1) takes value 1 if the household took the program loan in the cycle, that in column (2) takes value 1 if a household that was eligible to receive a program loan in the cycle took it, and that in column (3) takes the value 1 if a borrowing household repaid a loan taken in the cycle within 30 days of the due date. Explanatory variables include cycle dummies and landholding. Robust standard errors are in parentheses. ${ }^{* * *} p<0.01,{ }^{* *} p<0.05,{ }^{*} p<0.1$. 
Table 10: Selection: TRAIL

\begin{tabular}{lc}
\hline & Recommended \\
& \\
\hline & \\
Buy from Agent & 0.014 \\
& $(0.048)$ \\
Borrow from Agent & $0.148^{* * *}$ \\
& $(0.036)$ \\
Work for Agent & 0.006 \\
Non Hindu Household & $(0.053)$ \\
& 0.026 \\
Non Hindu Household $\times$ Agent Hindu & $(0.144)$ \\
& -0.099 \\
Scheduled Caste Household & $(0.133)$ \\
Scheduled Caste Household $\times$ Agent High Caste & $0.522^{* * *}$ \\
Scheduled Tribe Household & $(0.029)$ \\
& $-0.588^{* * *}$ \\
Scheduled Tribe Household $\times$ Agent High Caste & $(0.034)$ \\
Constant & $-0.190^{*}$ \\
& $(0.105)$ \\
& 0.202 \\
& $(0.158)$ \\
& 0.074 \\
Sample Size & $(0.094)$ \\
\hline
\end{tabular}

Notes:

Regressions are run on sample households (with at most 1.5 acres of land), following the specification in equation (2) in the text. The dependent variable takes value 1 if the household was recommended/selected into the scheme. Standard errors in parentheses are clustered at the village level. ${ }^{* * *}: p<0.01,{ }^{* *}: p<0.05,{ }^{*}: p<$ 0.1 . 


\section{Table 11: Interest Rate Comparisons}

(Dependent Variable: average interest rate paid on informal loans)

\begin{tabular}{lccc}
\hline & TRAIL & TRAIL & GBL \\
& $(1)$ & $(2)$ & $(3)$ \\
\hline & & & \\
Recommended & 0.003 & 0.019 & \\
Borrow from agent & $(0.015)$ & $(0.016)$ & \\
& & 0.041 & \\
Recommended $\times$ Borrow from agent & & $-0.033)$ & \\
Joined Group & & $(0.027)$ & \\
Constant & & & $0.046^{*}$ \\
& $0.207^{* * *}$ & $0.210^{* * *}$ & $0.337^{* * *}$ \\
& $(0.014)$ & $(0.013)$ & $(0.086)$ \\
\hline Sample Size & 448 & 448 & 424 \\
\hline
\end{tabular}

Notes:

Columns 1 and 2 present results from regression equation (3) on all sample households (with at most 1.5 acres) in TRAIL villages, column 3 from regression equation (4) on all sample households (with at most 1.5 acres) in GBL villages. The dependent variable is the average interest rate the household paid on production loans taken from traders or moneylenders in Cycle 1. Standard errors in parentheses are clustered at the village level. ${ }^{* * *}: p<0.01,^{* *}: p<0.05,{ }^{*}: p<0.1$. 


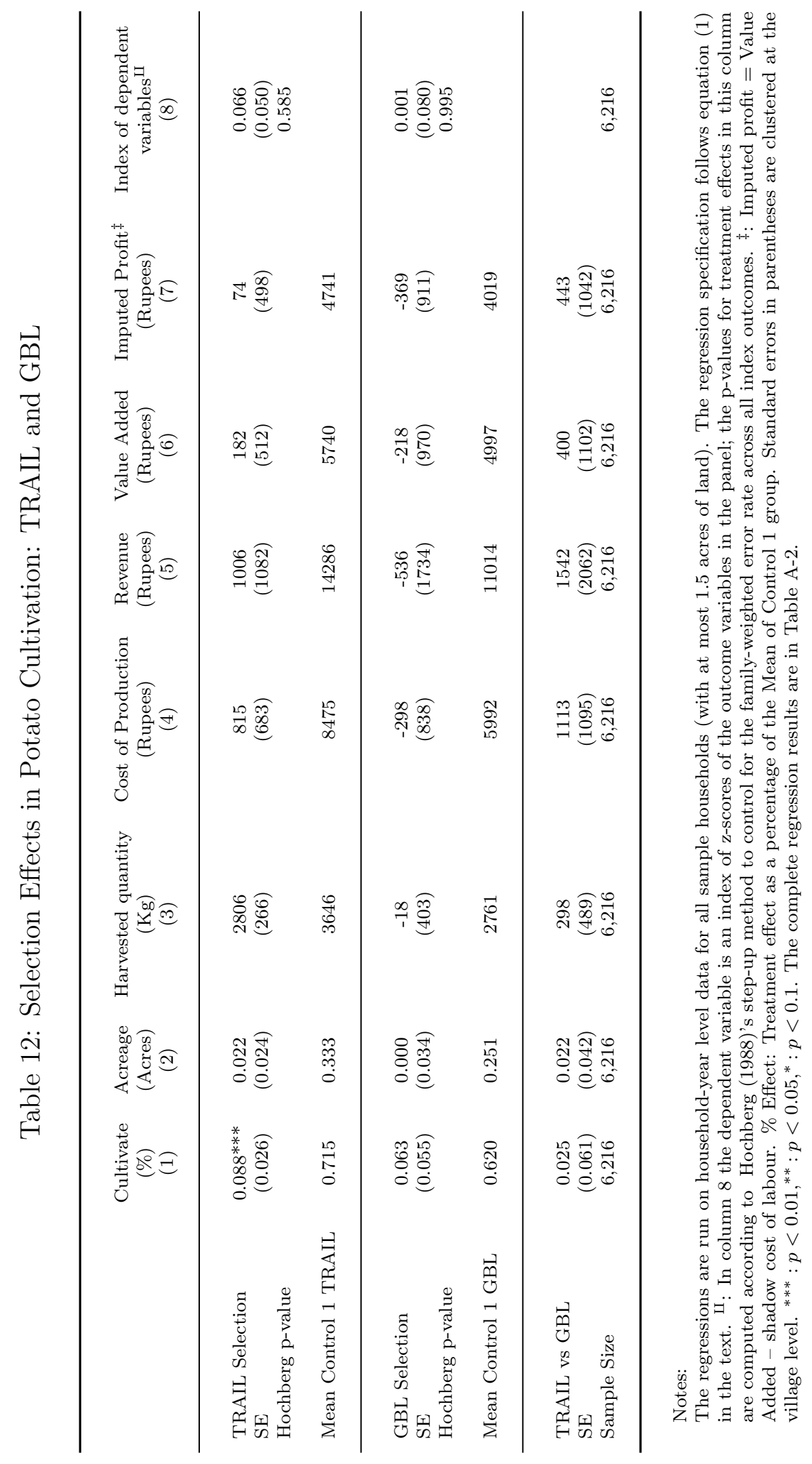




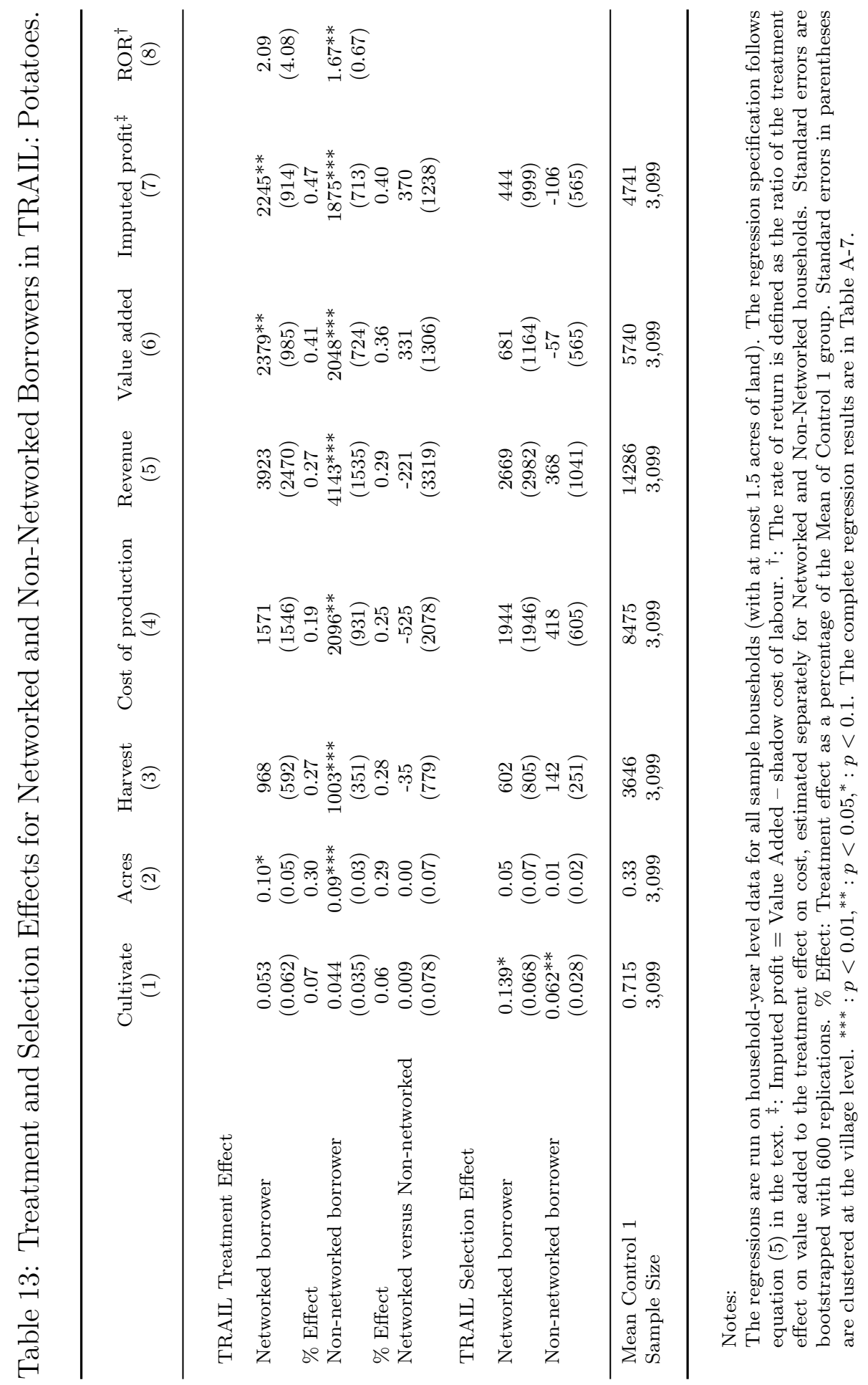




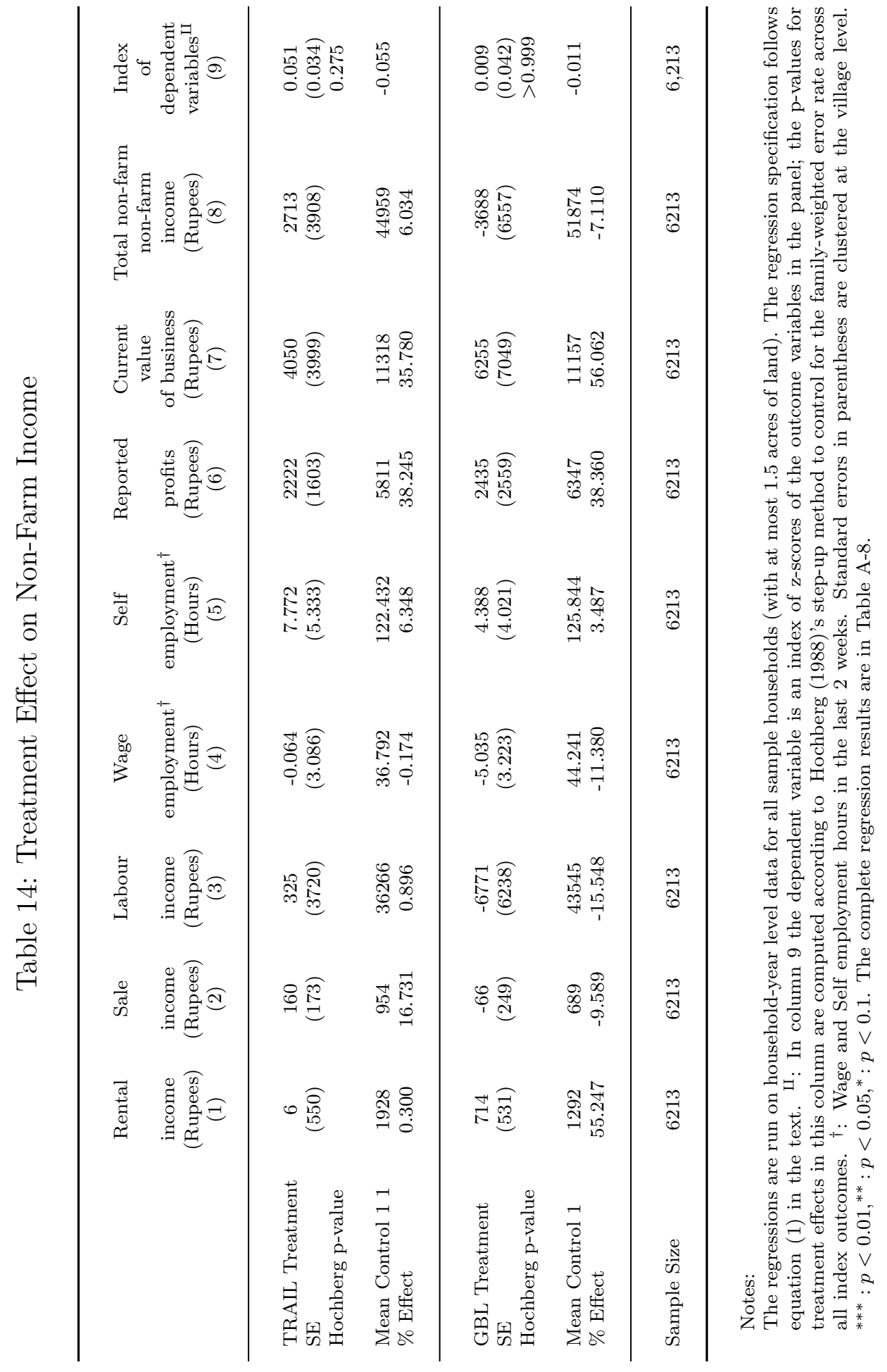




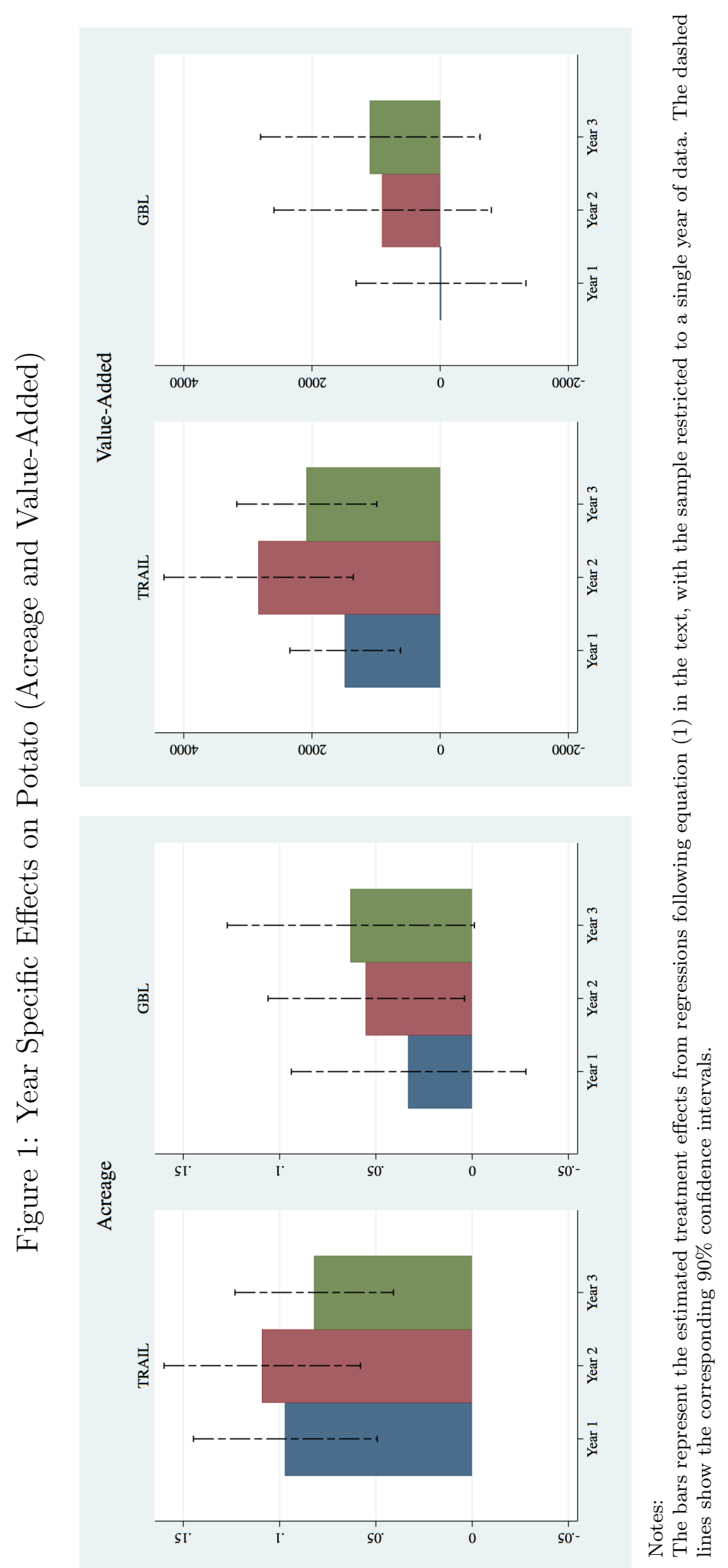


Figure 2: Heterogeneity in Treatment effects
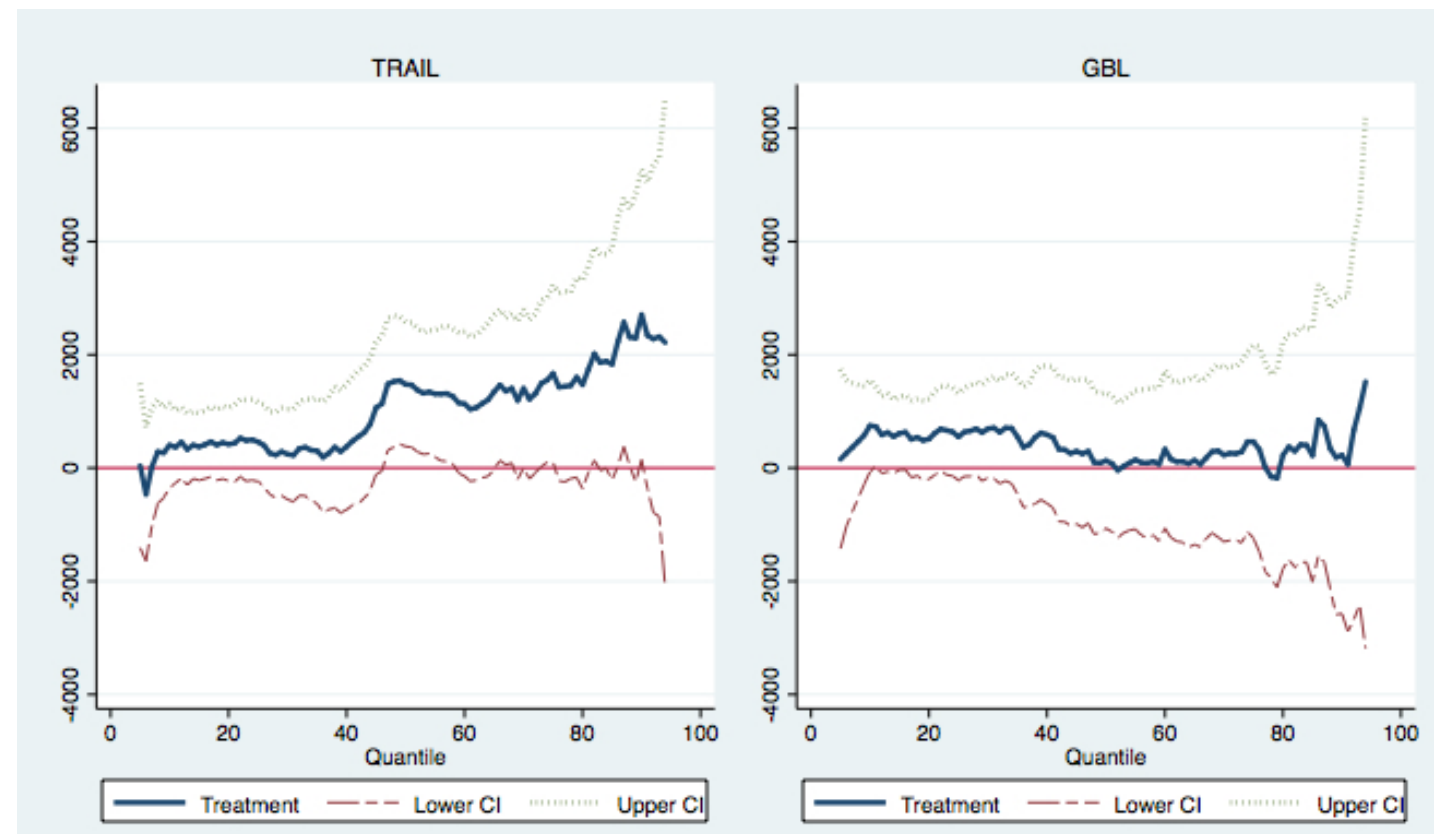

Notes:

The solid lines represent the estimated treatment effects at different quantiles of value-added, based on quantile regressions following the specification in equation (1) in the text. The dashed lines show the corresponding $90 \%$ confidence intervals. 


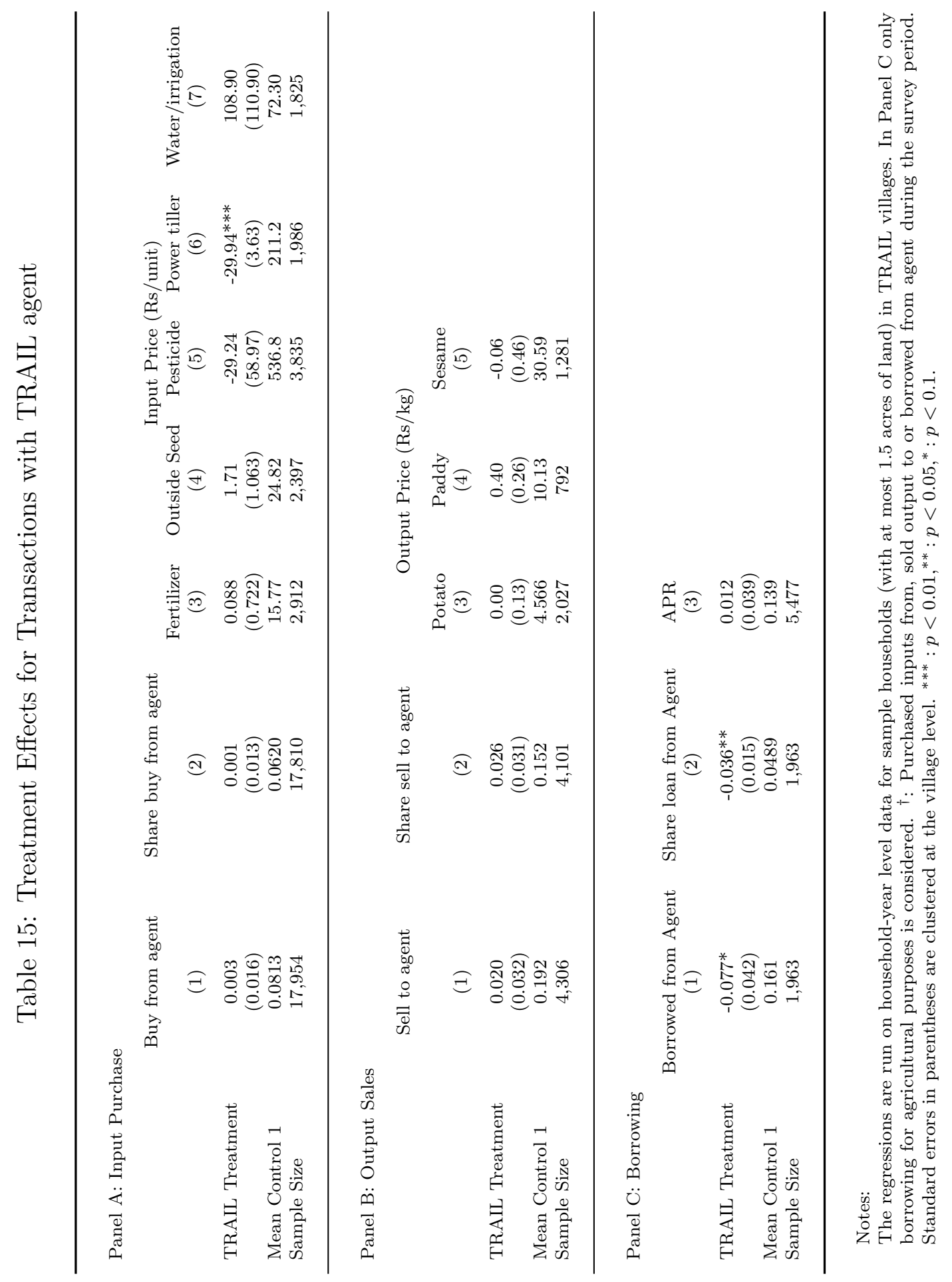


Table A-1: Program Impacts: Treatment Effects on Total Borrowing

\begin{tabular}{|c|c|c|c|}
\hline & $\begin{array}{l}\text { All Loans } \\
\text { (Rupees) } \\
(1)\end{array}$ & $\begin{array}{c}\text { Non Program Loans }{ }^{\dagger} \\
\text { (Rupees) } \\
(2)\end{array}$ & $\begin{array}{l}\text { Index of dependent } \\
\text { variables } \amalg \\
(3)\end{array}$ \\
\hline TRAIL & $\begin{array}{l}1,159.488 \\
(887.507)\end{array}$ & $\begin{array}{l}1,128.950 \\
(881.647)\end{array}$ & $\begin{array}{c}0.122 \\
(0.095)\end{array}$ \\
\hline TRAIL $\times$ Control 1 & $\begin{array}{c}30.663 \\
(436.498)\end{array}$ & $\begin{array}{c}44.701 \\
(429.516)\end{array}$ & $\begin{array}{l}0.004 \\
(0.046)\end{array}$ \\
\hline TRAIL $\times$ Treatment & $\begin{array}{c}5,131.269^{* * *} \\
(854.114)\end{array}$ & $\begin{array}{l}-242.453 \\
(382.101)\end{array}$ & $\begin{array}{c}0.246 \\
(0.059)^{* *}\end{array}$ \\
\hline GBL $\times$ Control 1 & $\begin{array}{c}336.967 \\
(713.466)\end{array}$ & $\begin{array}{c}259.605 \\
(724.418)\end{array}$ & $\begin{array}{c}0.032 \\
(0.077)\end{array}$ \\
\hline GBL $\times$ Treatment & $\begin{array}{c}4,037.667^{* * *} \\
(1,061.609)\end{array}$ & $\begin{array}{c}63.268 \\
(704.441)\end{array}$ & $\begin{array}{c}0.208 \\
(0.088)^{*}\end{array}$ \\
\hline Landholding & $\begin{array}{c}9,674.853^{* * *} \\
(844.426)\end{array}$ & $\begin{array}{c}8,871.657^{* * *} \\
(815.150)\end{array}$ & $\begin{array}{c}0.990 \\
(0.088)^{* *}\end{array}$ \\
\hline Year 2 & $\begin{array}{c}-632.356^{* * *} \\
(216.794)\end{array}$ & $\begin{array}{c}-1,194.769^{* * * *} \\
(196.680)\end{array}$ & $\begin{array}{c}-0.099 \\
(0.021)^{* *}\end{array}$ \\
\hline Year 3 & $\begin{array}{c}-949.663^{* *} \\
(357.424)\end{array}$ & $\begin{array}{c}-955.477^{* * *} \\
(323.253)\end{array}$ & $\begin{array}{c}-0.102 \\
(0.036)^{* *}\end{array}$ \\
\hline Information Village & $\begin{array}{c}878.913 \\
(870.330)\end{array}$ & $\begin{array}{c}738.466 \\
(801.285)\end{array}$ & $\begin{array}{c}0.086 \\
(0.089)\end{array}$ \\
\hline Constant & $\begin{array}{c}53.063 \\
(694.167)\end{array}$ & $\begin{array}{c}694.151 \\
(670.831)\end{array}$ & $\begin{array}{c}-0.530 \\
(0.073)^{* *}\end{array}$ \\
\hline TRAIL Treatment & $\begin{array}{c}5101^{* * *} \\
(1032)\end{array}$ & $\begin{array}{l}-287.2 \\
(620.9)\end{array}$ & $\begin{array}{c}0.242 \\
(0.082)\end{array}$ \\
\hline $\begin{array}{l}\text { Hochberg p-value } \\
\text { Mean Control } 1 \text { TRAIL } \\
\text { \%Effect (TRAIL) }\end{array}$ & $\begin{array}{l}5548 \\
0.919\end{array}$ & $\begin{array}{c}5548 \\
-0.052\end{array}$ & $\begin{array}{l}0.025 \\
0.022\end{array}$ \\
\hline $\begin{array}{l}\text { GBL Treatment } \\
\text { SE Treatment } \\
\text { Hochberg p-value } \\
\text { Mean Control } 1 \text { GBL } \\
\text { \%Effect (GBL) }\end{array}$ & $\begin{array}{c}3701 * * * \\
(1079) \\
\\
4039 \\
0.916\end{array}$ & $\begin{array}{c}-196.3 \\
(766.4) \\
4039 \\
-0.049\end{array}$ & $\begin{array}{c}0.176 \\
(0.092) \\
0.368 \\
-0.140\end{array}$ \\
\hline TRAIL Selection & $\begin{array}{c}30.66 \\
(436.5)\end{array}$ & $\begin{array}{c}44.70 \\
(429.5)\end{array}$ & \\
\hline GBL Selection & $\begin{array}{l}337.0 \\
(713.5)\end{array}$ & $\begin{array}{l}259.6 \\
(724.4)\end{array}$ & \\
\hline Sample Size & 6,210 & 6,210 & 6,210 \\
\hline
\end{tabular}

Notes:

Standard errors, clustered at the village level are in parentheses. ${ }^{* * *}: p<0.01,{ }^{* *}: p<$ $0.05,{ }^{*}: p<0.1$. Sample restricted to households with at most 1.5 acres. ${ }^{\amalg}$ : Column 3 presents the TRAIL and GBL treatment effects in a regression on treatment of an index of zscores of the outcome variables in the panel following Kling, Liebman, and Katz (2007); $p$-values for this regression are reported using Hochberg's stepup method to control the FWER across all index outcomes. ${ }^{\dagger}$ : Non-Program loan refers to loans from other sources. 


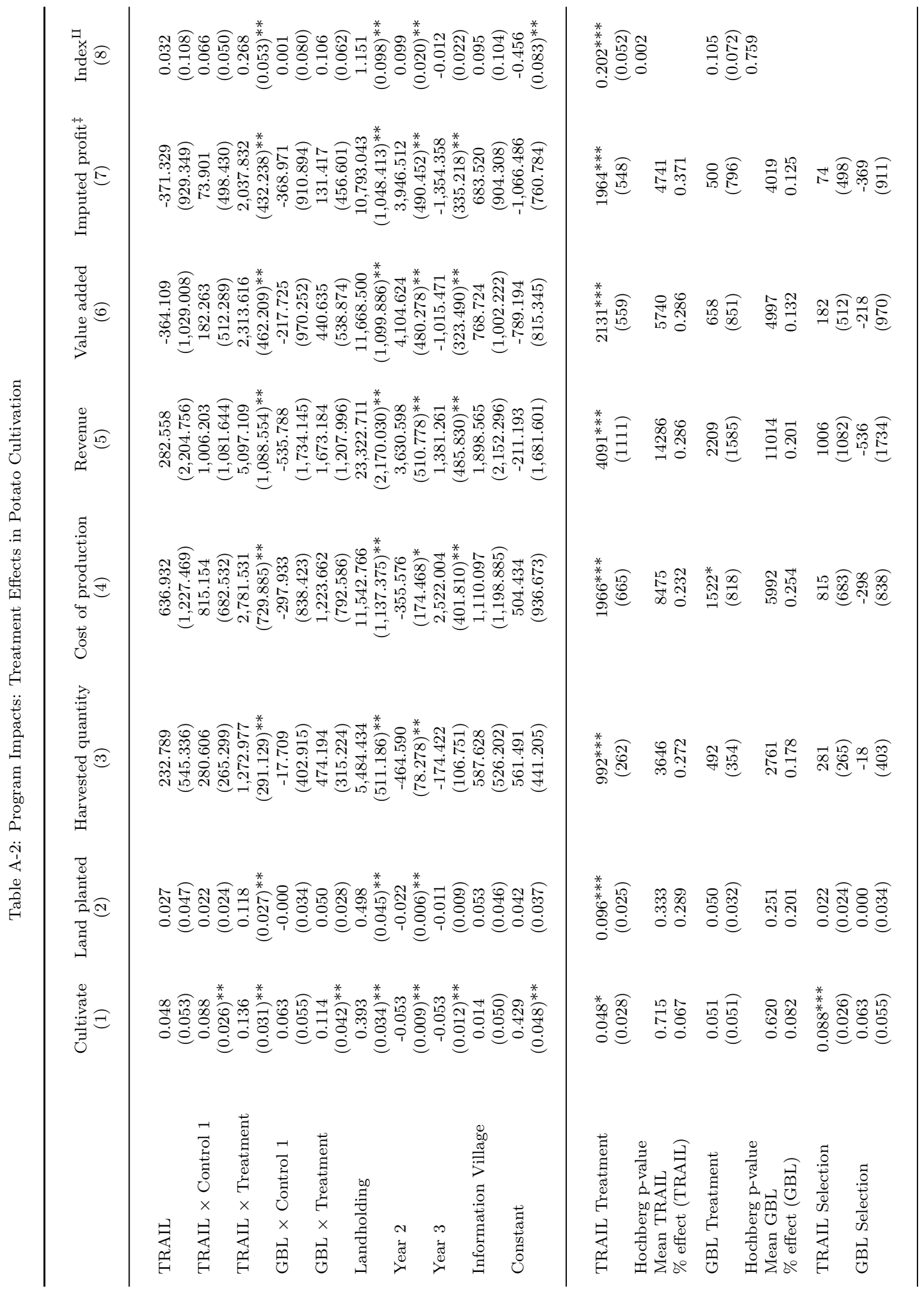




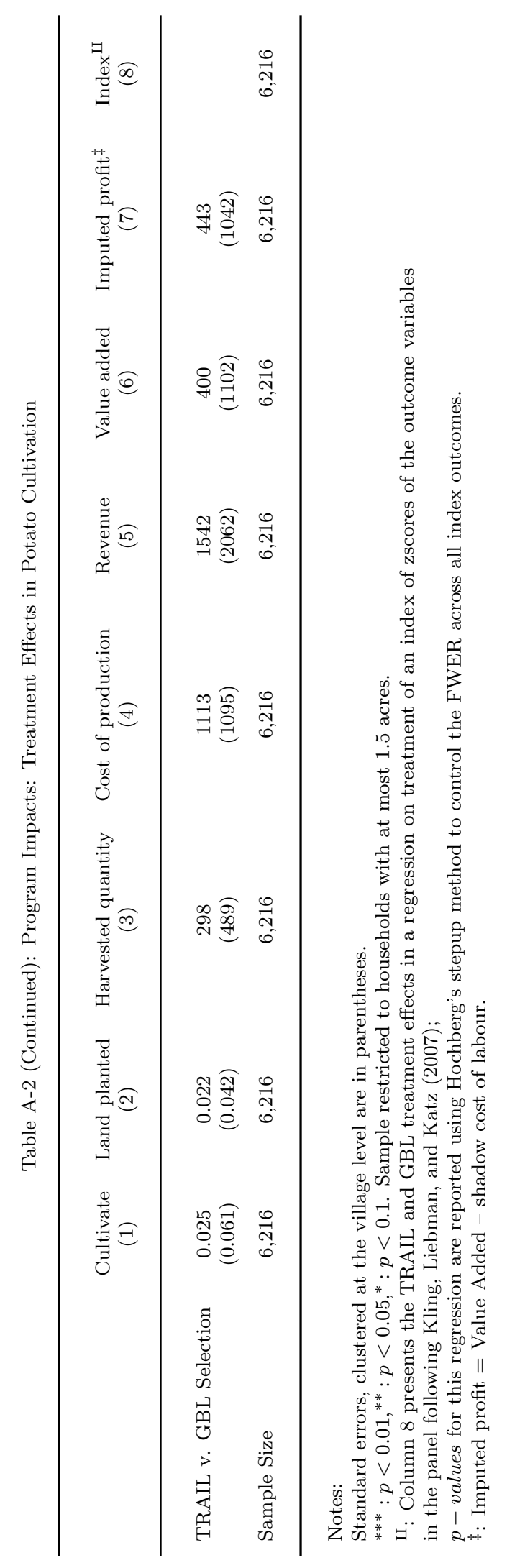




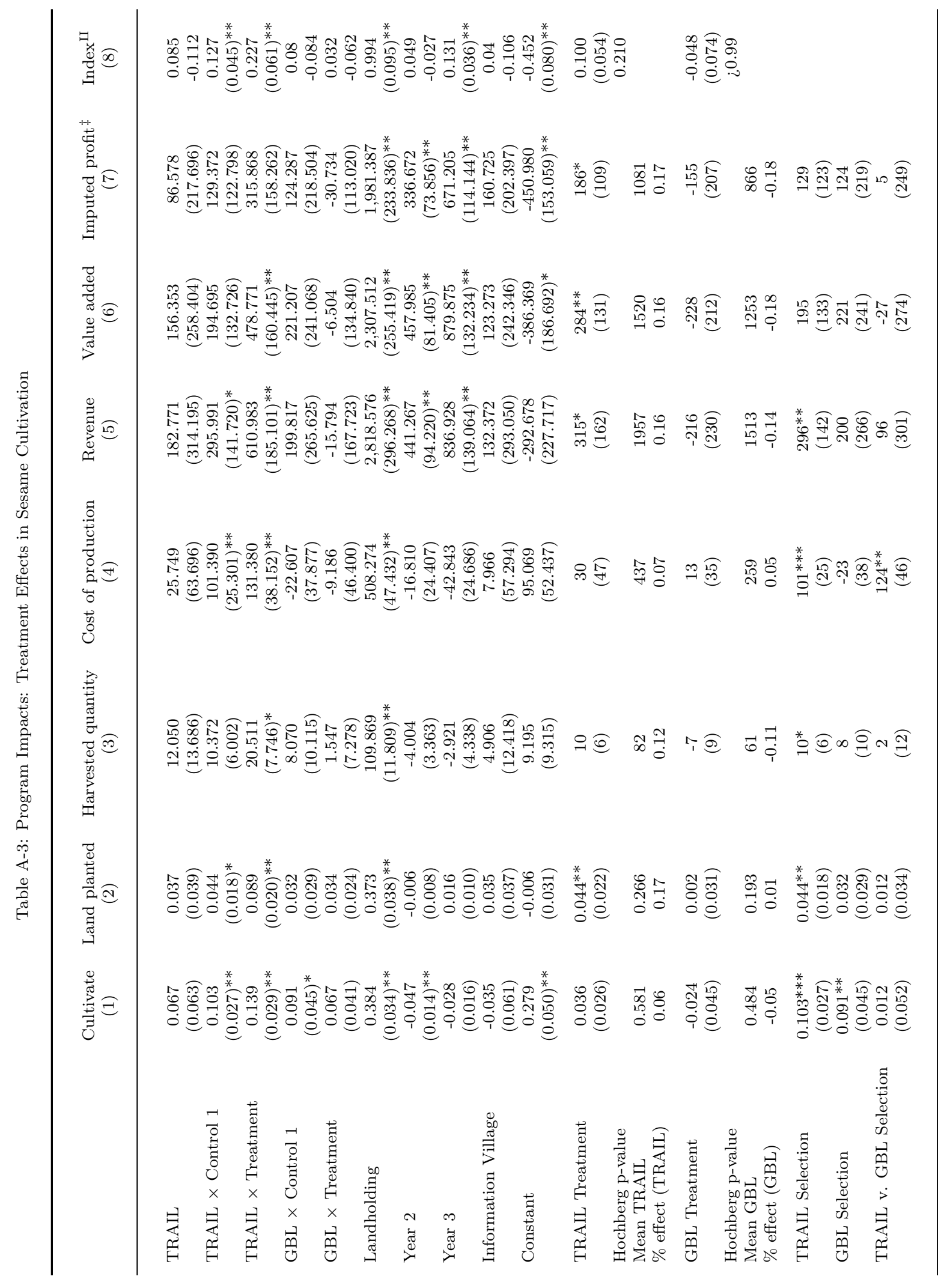




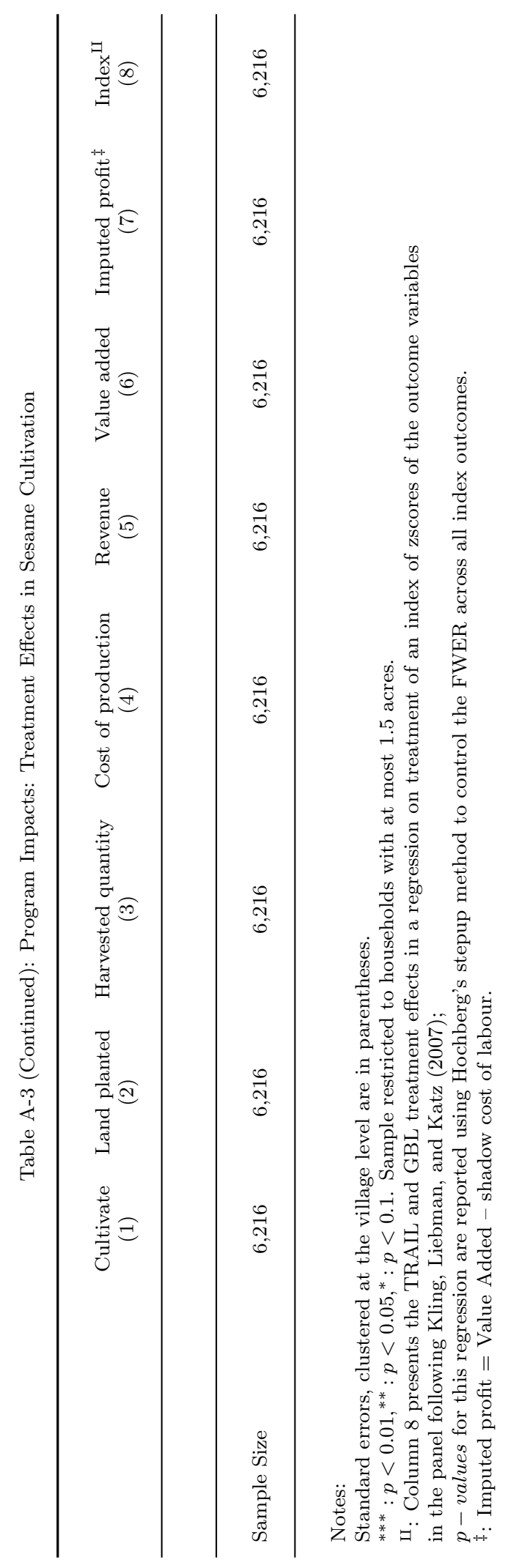




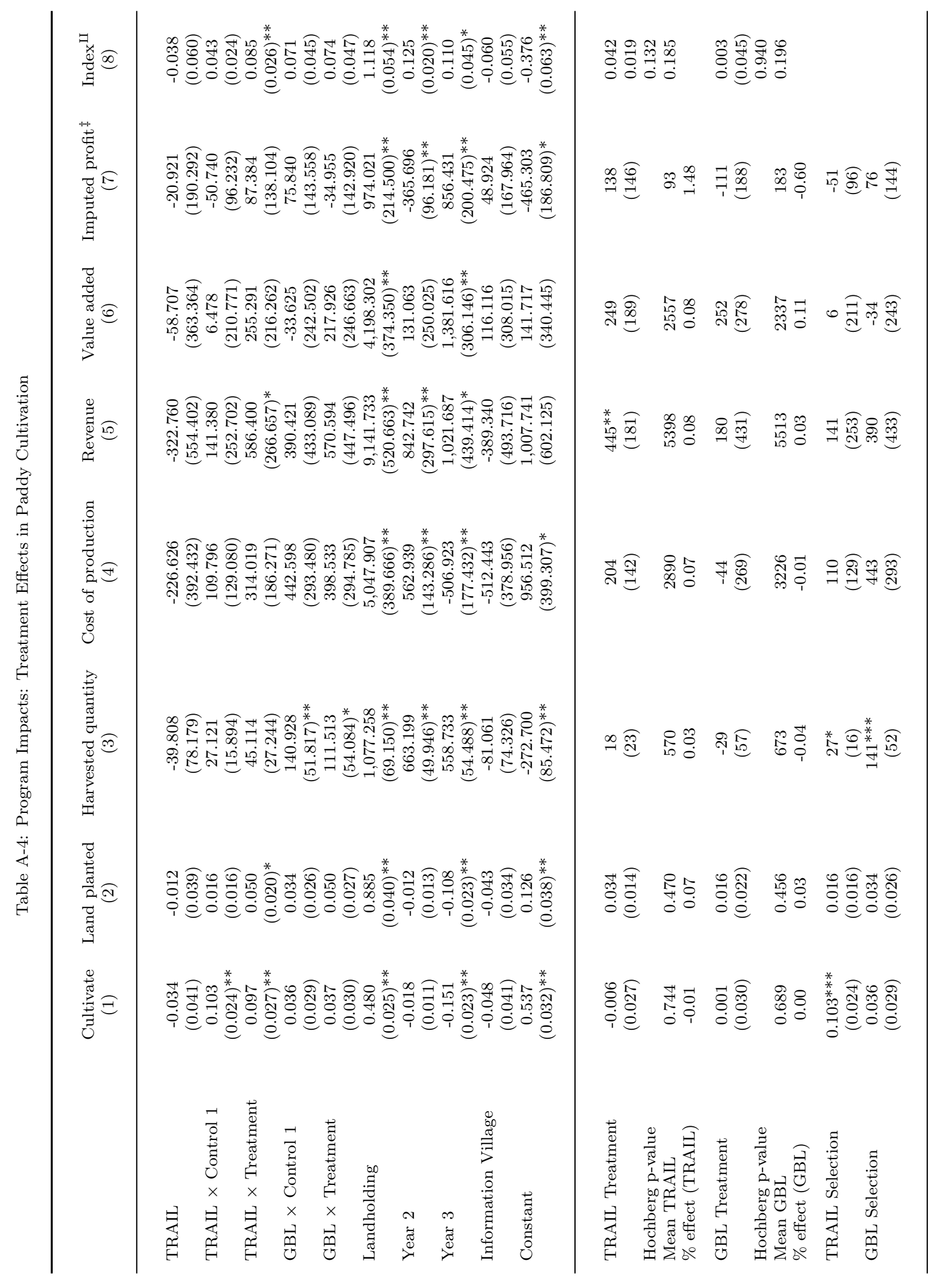




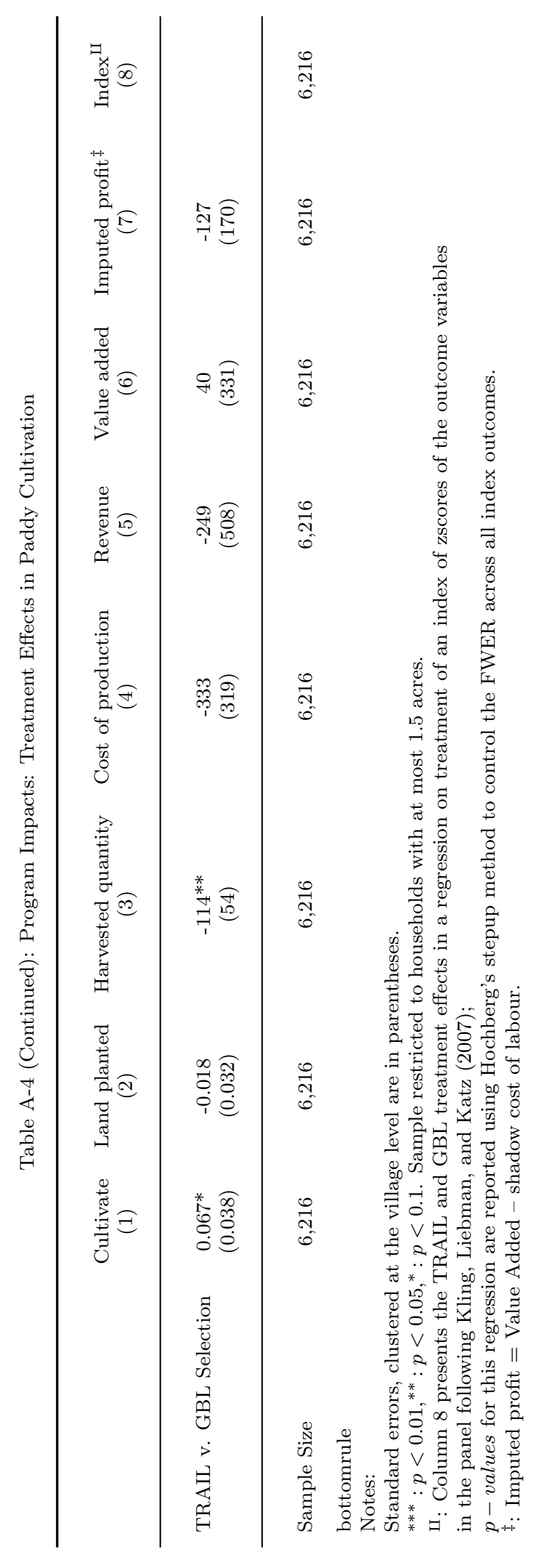




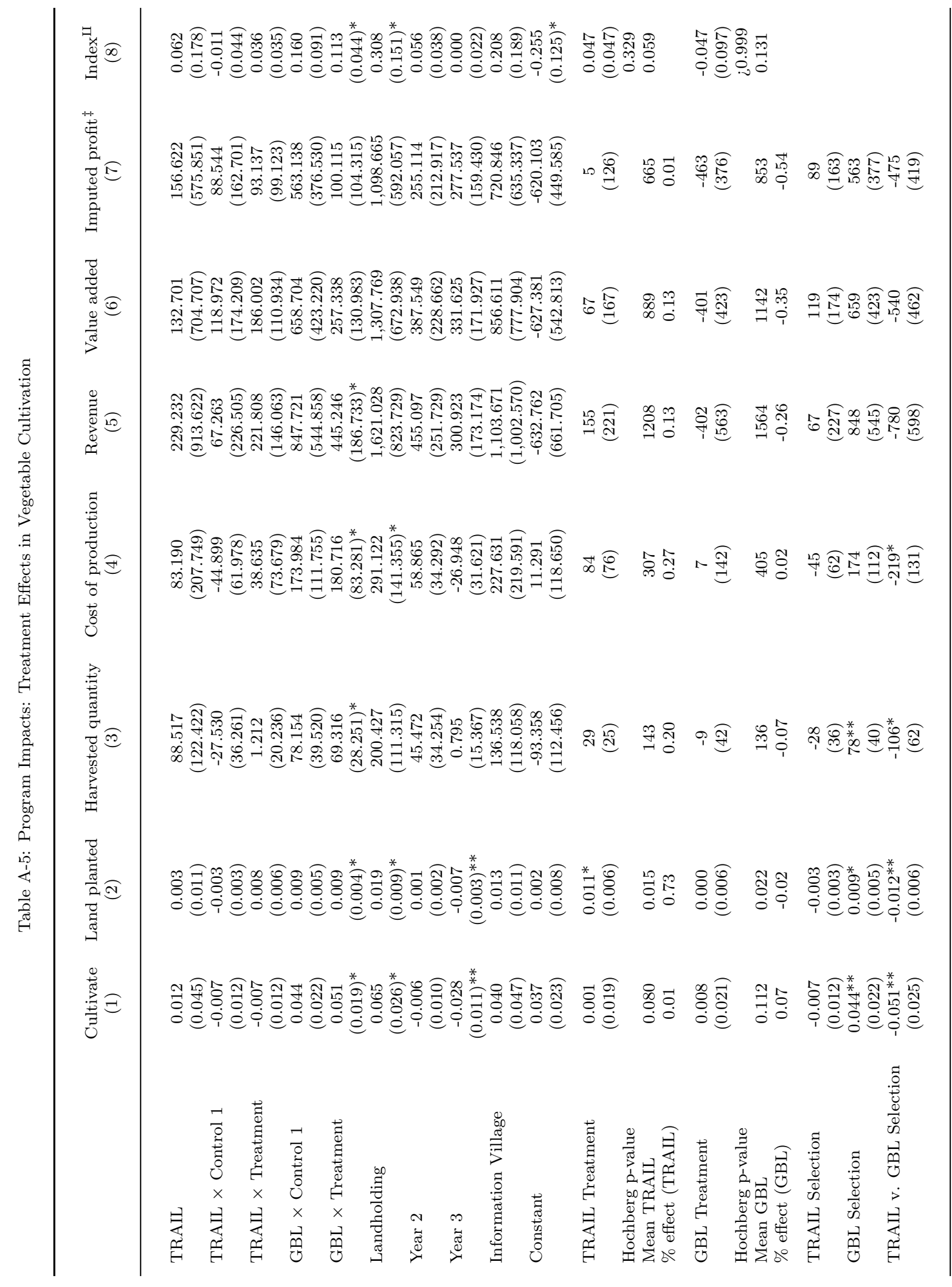




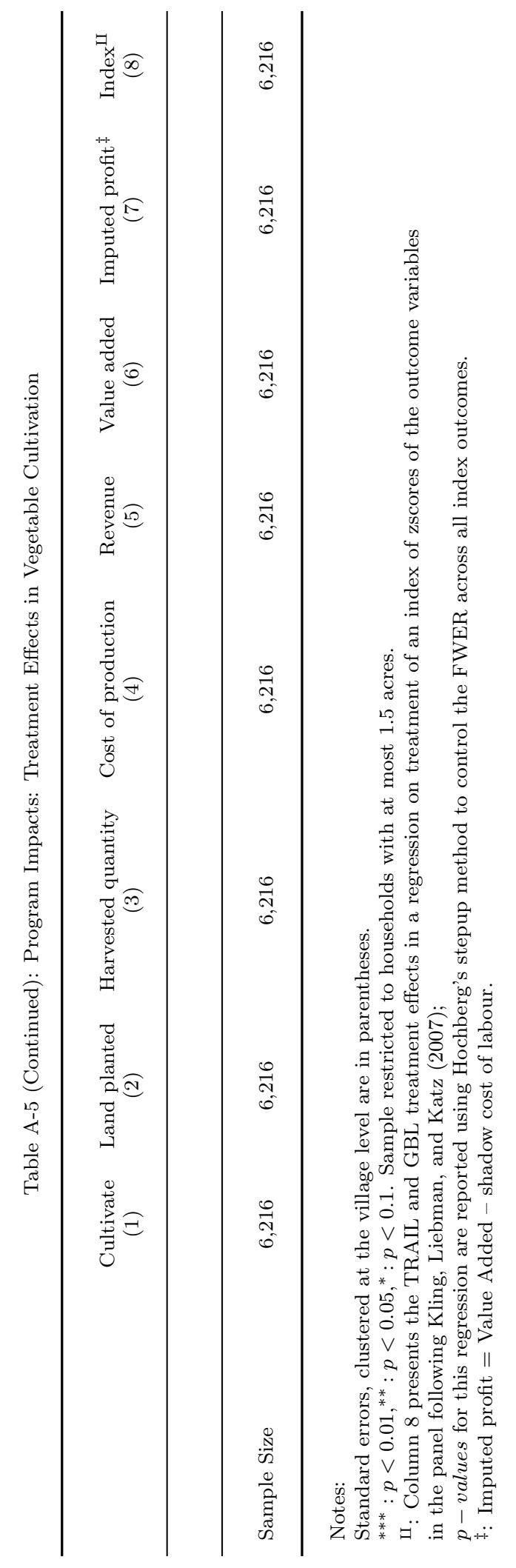


Table A-6: Program Impacts: Treatment Effects in Aggregate Farm Value-Added

\begin{tabular}{|c|c|}
\hline & $\begin{array}{c}\text { Farm Value-Added } \\
(1)\end{array}$ \\
\hline TRAIL & $\begin{array}{c}-90.733 \\
(0.09)\end{array}$ \\
\hline TRAIL $\times$ Control 1 & $\begin{array}{c}484.707 \\
(0.74)\end{array}$ \\
\hline TRAIL $\times$ Treatment & $\begin{array}{l}2,925.27 \\
(5.01)^{* *}\end{array}$ \\
\hline GBL $\times$ Control 1 & $\begin{array}{c}878.289 \\
(0.73)\end{array}$ \\
\hline GBL $\times$ Treatment & $\begin{array}{c}905.147 \\
(1.33)\end{array}$ \\
\hline Landholding & $\begin{array}{l}16,707.69 \\
(15.42)^{* *}\end{array}$ \\
\hline Year 2 & $\begin{array}{l}4,559.08 \\
(8.35)^{* *}\end{array}$ \\
\hline Year 3 & $\begin{array}{c}747.472 \\
(1.67)\end{array}$ \\
\hline Information Village & $\begin{array}{l}1,673.62 \\
(1.72)\end{array}$ \\
\hline Constant & $\begin{array}{c}-2,261.63 \\
(2.77)^{* *}\end{array}$ \\
\hline TRAIL Treatment & $\begin{array}{c}2441^{* * *} \\
(678)\end{array}$ \\
\hline $\begin{array}{l}\text { Mean TRAIL } \\
\% \text { Effect (TRAIL) }\end{array}$ & $\begin{array}{l}8324 \\
0.293\end{array}$ \\
\hline GBL Treatment & $\begin{array}{c}27 \\
(1114)\end{array}$ \\
\hline $\begin{array}{l}\text { Mean GBL } \\
\% \text { Effect }(\mathrm{GBL})\end{array}$ & $\begin{array}{l}7742 \\
0.003\end{array}$ \\
\hline TRAIL Selection & $\begin{array}{c}485 \\
(654)\end{array}$ \\
\hline GBL Selection & $\begin{array}{c}878 \\
(1197)\end{array}$ \\
\hline TRAIL v. GBL Selection & $\begin{array}{c}-394 \\
(1363)\end{array}$ \\
\hline Sample Size & 6,213 \\
\hline \multicolumn{2}{|c|}{$\begin{array}{l}\text { Notes: } \\
\text { Standard errors, clustered at the village level are } \\
\text { in parentheses. }{ }^{* * *}: p<0.01,^{* *}: p<0.05,^{*} \\
p<0.1 \text {. Sample restricted to households with } \\
\text { at most } 1.5 \text { acres. }\end{array}$} \\
\hline
\end{tabular}




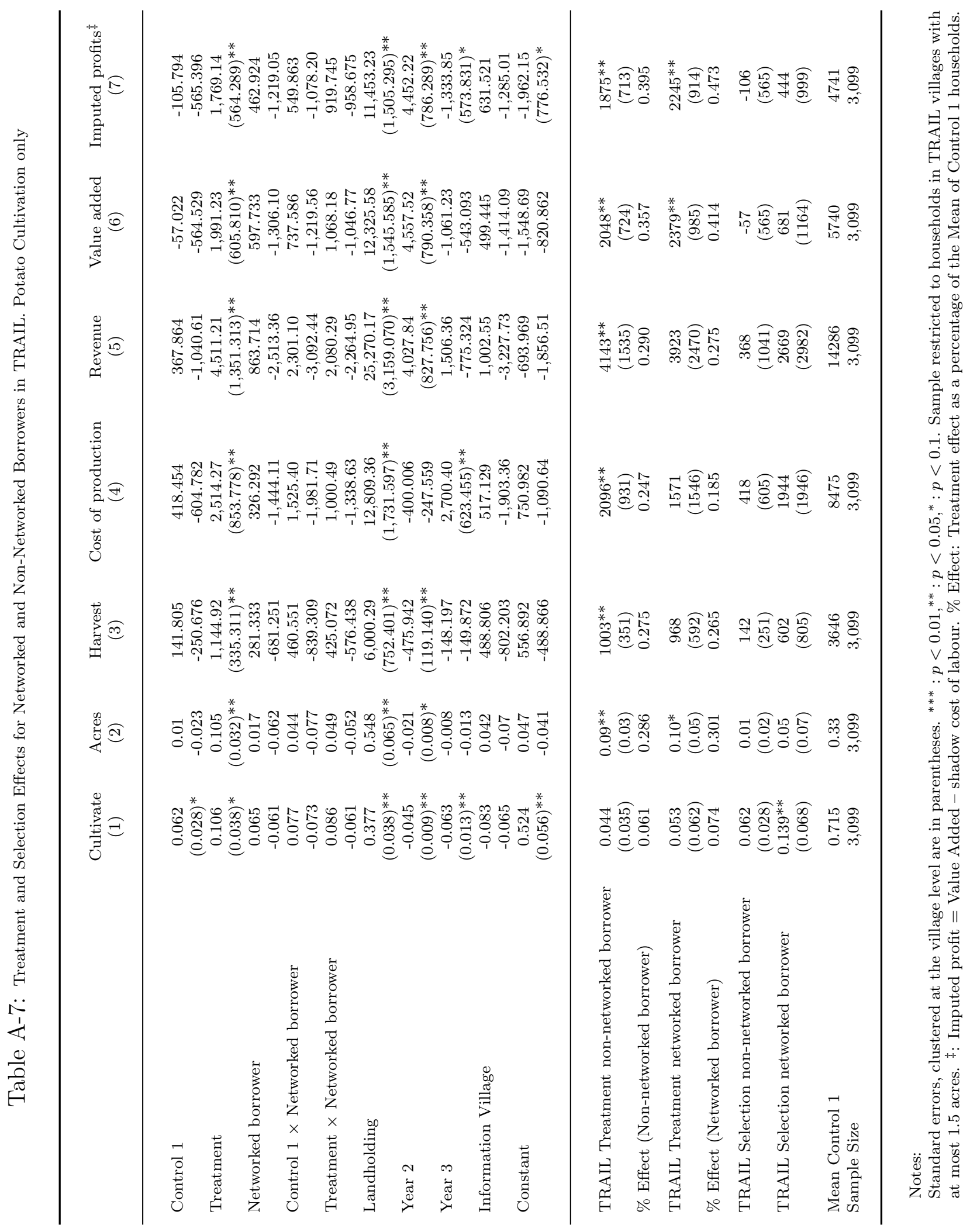




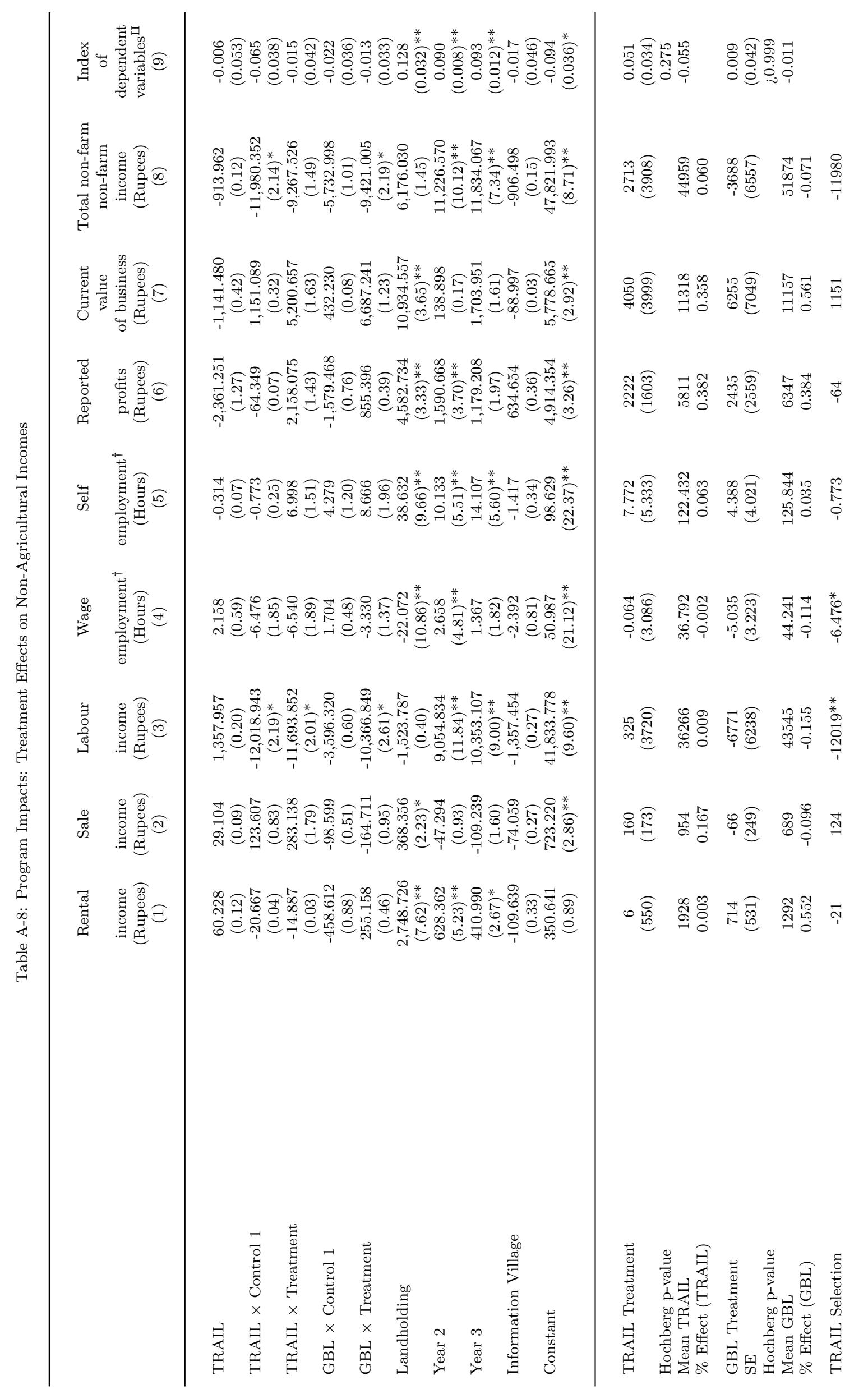




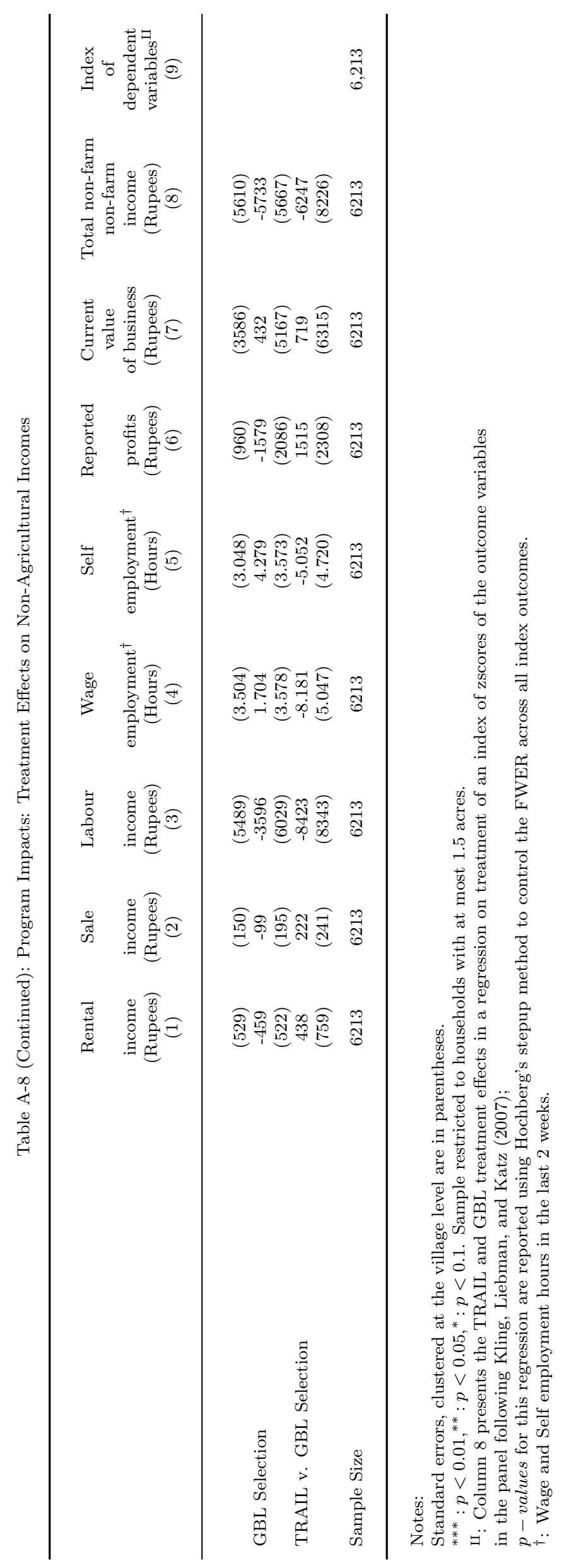

